\title{
VIVIANI BARNABÉ
}

\section{Efeitos da atividade física intensa e moderada sobre o enfisema pulmonar}

\author{
Tese apresentada à Faculdade de \\ Medicina da Universidade de São \\ Paulo para obtenção do título de \\ Doutor em Ciências
}

Programa de: Ciências Médicas

Área de concentração: Educação e Saúde

Orientador: Prof. Dr. Milton de Arruda Martins

São Paulo 


\section{VIVIANI BARNABÉ}

\section{Efeitos da atividade física intensa e moderada sobre o enfisema pulmonar}

Tese apresentada à Faculdade de Medicina da Universidade de São Paulo para obtenção do título de Doutor em Ciências.

Área de concentração: Educação e Saúde

Orientador: Prof. Dr. Milton de Arruda Martins 
Dados Internacionais de Catalogação na Publicação (CIP)

Preparada pela Biblioteca da

Faculdade de Medicina da Universidade de São Paulo

Creprodução autorizada pelo autor

Barnabé, Viviani

Efeitos da atividade física intensa e moderada sobre o enfisema pulmonar / Viviani Barnabé. -- São Paulo, 2010.

Tese(doutorado)--Faculdade de Medicina da Universidade de São Paulo.

Programa de Ciências Médicas. Área de concentração: Educação e Saúde.

Orientador: Milton de Arruda Martins.

Descritores: 1.Enfisema pulmonar 2.Doença pulmonar obstrutiva crônica 3.Atividade física 4.Reabilitação 5.Ratos Wistar

USP/FM/DBD-342/10 
DEDICATÓRIA 
A minha família, pelo amor e dedicação 
em todos os momentos. 
AGRADECIMENTOS

À Deus, por me possibilitar esta caminhada e me prover de condições físicas, emocionais e intelectuais para chegar até este momento.

Aos meus pais, pela dedicação, ensinamentos e lições de vida. Por terem me ensinado a pescar o peixe. Sou muito grata.

À minha irmã, pelo companheirismo de sempre, pelo bom humor e apoio incondicional. E ao meu cunhado "Espanhol", pela pessoa humana e amiga que é.

Aos meus filhos, Guilherme e Henrique, pelo amor e pelas lições que aprendi com eles as quais me fizeram uma pessoa melhor, mais tolerante, mais compreensiva e mais feliz; amo vocês.

Ao Prof. Milton de Arruda Martins, meu orientador, minha admiração e gratidão pelos ensinamentos profissionais e pelos exemplos de caráter e retidão.

À Fernanda Deggobi Tenório Quirino dos Santos Lopes, co-autora deste trabalho, me acompanhou nesta longa jornada e me auxiliou a slucionar minhas dificuldades.

À Beatriz Saraiva-Romanholo, amiga inestimável, fundamental na conclusão deste trabalho. Sempre com bons conselhos e uma bondade divina, sou eternamente grata. 
À Maria do Patrocínio Tenório Nunes, minha amiga, banca da minha qualificação, pessoa inteligente, perspicaz, sempre com boas sugestões.

Amigos e companheiros de pesquisa, Clarisse, Carla, Alessandra Choqueta, Rogério entre outros, que além do carinho, estiveram sempre dispostos a auxiliar e colaborar para o bom andamento do trabalho.

Aos alunos da V'NICID que participaram em momentos diferentes do desenvolvimento do trabalho, meu muito obrigada.

À Tatiana Pecego Grillo, que bom poder contar com sua amizade, sempre! Sua colaboração no trabalho foi fundamental, em vários momentos.

Ao Corpo Administrativo do LIM-20, sempre solícitos, meus sinceros agradecimentos. 


\section{EPÍGRAFE}


Que Deus não permita que eu perca o ROMANTISMO, mesmo eu sabendo que as rosas não falam.

Que eu não perca o OTIMISMO, mesmo sabendo que o futuro que nos espera não é assim tão alegre Que eu não perca a VONTADE DE VIVER, mesmo sabendo que a vida é, em muitos momentos, dolorosa...

Que eu não perca a vontade de TER GRANDES AMIGOS, mesmo sabendo que, com as voltas do mundo, eles acabam indo embora de nossas vidas...

Que eu não perca a vontade de AJUDARAS PESSOAS, mesmo sabendo que muitas delas são incapazes de ver, reconhecer e retribuir esta ajuda.

Que eu não perca o EQVILÍBRIO, mesmo sabendo que inúmeras forças querem que eu caia Que eu não perca a VONTADE DE AMAR, mesmo sabendo que a pessoa que eu mais amo, pode não sentir o mesmo sentimento por mim... Que eu não perca a LUZ e o BRILHO NO OLHAR, mesmo sabendo que muitas coisas que verei no mundo, escurecerão meus olhos...

Que eu não perca a GARRA, mesmo sabendo que a derrota e a perda são dois adversários extremamente perigosos. Que eu não perca a RAZ̃̃̃, mesmo sabendo que as tentações da vida são inúmeras e deliciosas. Que eu não perca o SENTIMENTOO DE JUSTIÇA, mesmo sabendo que o prejudicado possa ser eu. 
mesmo sabendo que um dia meus braços estarão fracos...

Que eu não perca a BELEZA E A ALEGRIA DE VER, mesmo sabendo que muitas lágrimas brotarão dos meus olhos e escorrerão por minha alma... Que eu não perca o AMORPOR MINHA FAMÍLIA, mesmo sabendo que ela muitas vezes me exigiria esforços incríveis para manter a sua harmonia. Que eu não perca a vontade de DOARESTE ENORME AMOR que existe em meu coração, mesmo sabendo que muitas vezes ele será submetido e até rejeitado. Que eu não perca a vontade de SER GRANDDE, mesmo sabendo que o mundo é pequeno...

E acima de tudo...

Que eu jamais me esqueça que Deus me ama infinitamente, que um pequeno grão de alegria e esperança dentro de cada um é capaz de mudar e transformar qualquer coisa, pois.... A VIDA É CONSTRVÍDA NOS SONHOS E CONCRETIZADA NO AMOR! Amorosamente, Francisco Cândido Xavier 
Esta dissertação está de acordo com:

Referências: adaptado de International Committee of Medical Journals Editors (Vancouver)

Universidade de São Paulo. Faculdade de Medicina. Serviço de Biblioteca e Documentação. Guia de apresentação de dissertações, teses e monografias. Elaborado por Anneliese Carneiro da Cunha, Maria Julia de A. L. Freddi, Maria F. Crestana, Marinalva de Souza Aragão, Suely Campos Cardoso, Valéria Vilhena. São Paulo: Serviço de Biblioteca e Documentação; 2005.

Abreviaturas dos títulos dos periódicos de acordo com List of Journals Indexed in Index Medicus. 
LISTA DE FIGURAS

RESUMO

SUMMARY

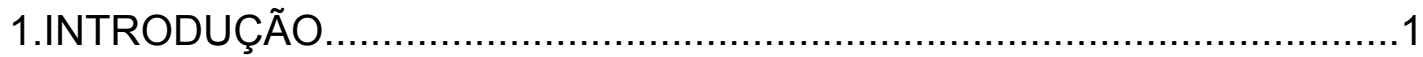

1.1DPOC

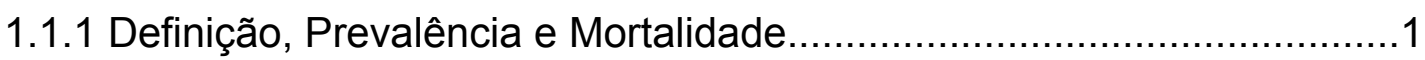

1.1.2 Etiologia, Quadro Clínico e Classificação...............................................

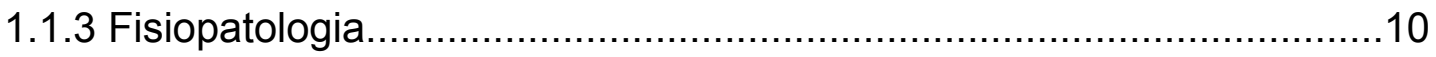

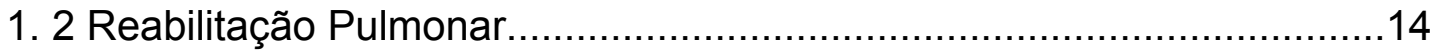

1.2.2 Atividade Fisica Aeróbica................................................................

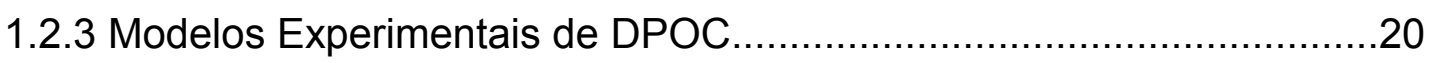

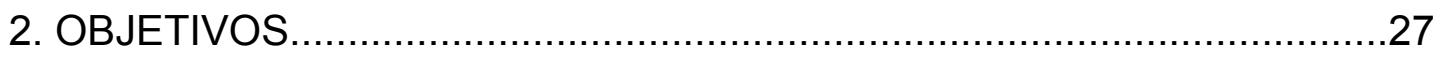

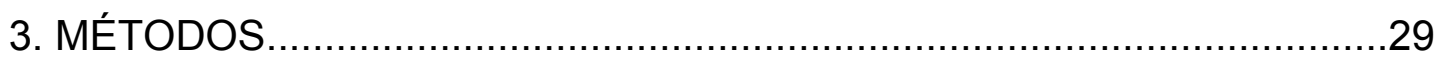

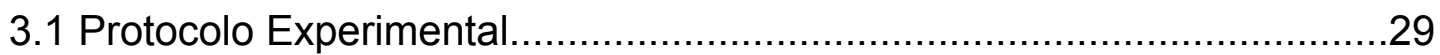

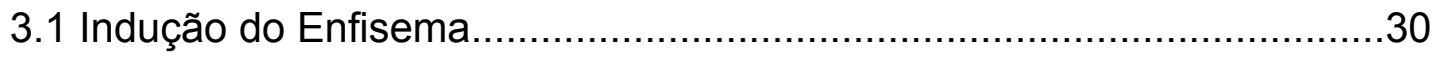

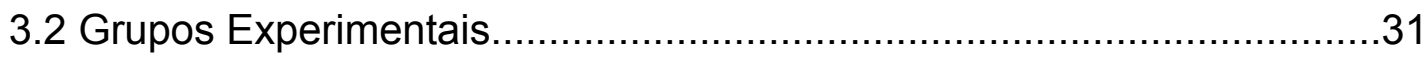

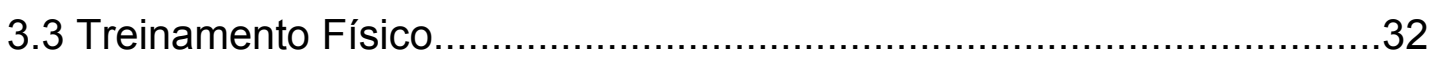

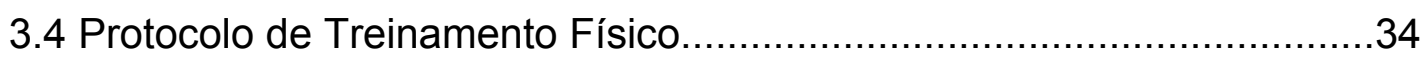

3.5 Avaliação da Mecânica Pulmonar..........................................................35

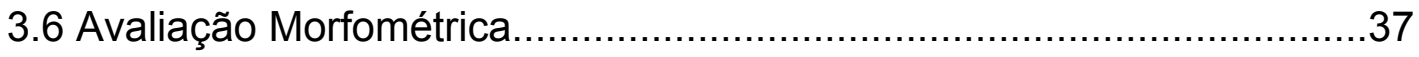

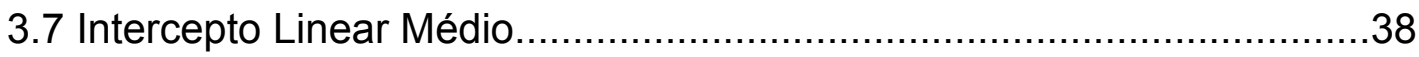

3.8 Mensuração de Fibras Colágenas e Elásticas no Parênquima

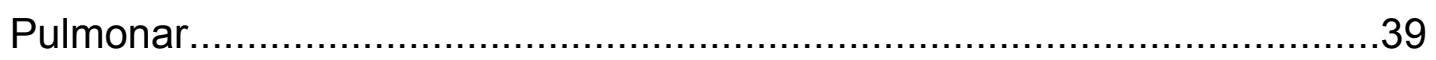




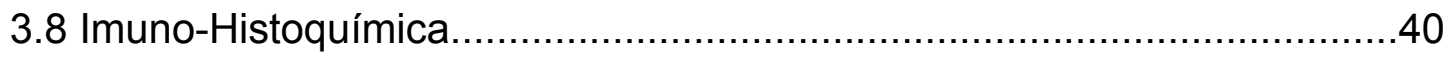

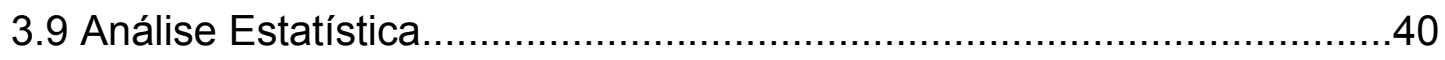

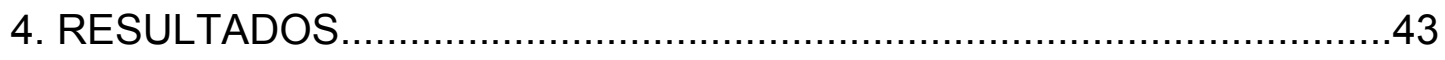

4.1 Peso Corpóreo dos Animais................................................43

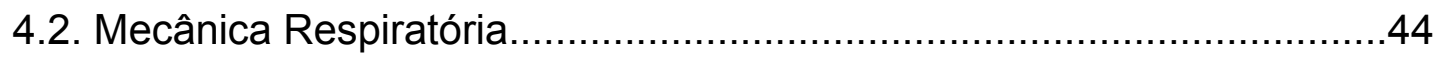

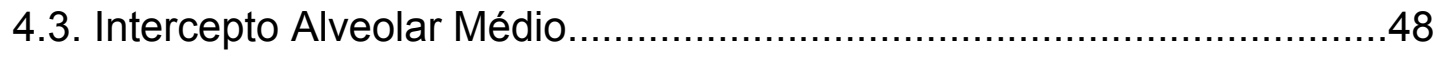

4.4. Proporção de Fibras Colágenas no Parênquima Pulmonar..................51

4.4 Análise da Expressão de Isoprostano-8.....................................53

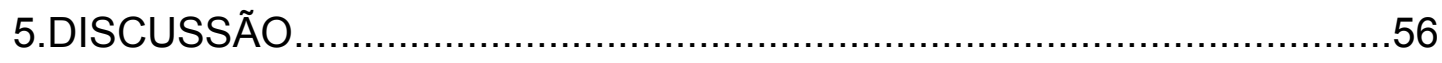

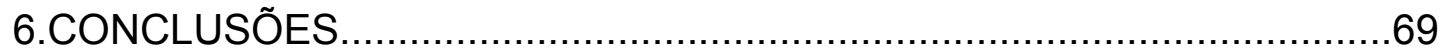

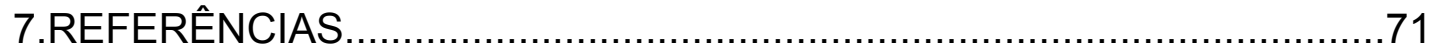




\section{LISTA DE FIGURAS}

Figura 1 (A) e (B) Fotos da esteira ergométrica adaptada para ratos, com os animais em treinamento 33

Figura 2 Sistema para medida de mecânica pulmonar em pequenos animais (Flexivent-Scireq)

Figura 3 Fotos A e B do retículo utilizado para quantificação do diâmetro alveolar médio e de uma fatia de tecido pulmonar sem sobreposição do retículo.

Figura 4 Gráfico do peso corpóreo dos cinco grupos de animais.

Figura 5 Gráfico da Resistência do sistema respiratório (Rrs) inicial e final dos cinco grupos estudados.

Figura 6 Gráfico dos valores da elastância do sistema respiratório (Ers)

inicial e final nos cinco grupos experimentais.

Figura 7 Valores de Lm (média e desvio padrão) nos cinco grupos

Experimentais

Figura 8 Fotomicrografias do parênquima pulmonar dos animais dos 5 grupos experimentais .50

Figura 9 Valores da proporção de fibras de colágeno (média e desvio padrão) no parênquima alveolar nos cinco grupos experimentais 52

Figura 10 Valores referentes à intensidade da expressão do Isoprostano-8 no parênquima alveolar dos cinco grupos experimentais. 
RESUMO 
Barnabé, V. Efeitos da atividade física intensa e moderada sobre o enfisema pulmonar [Tese]. São Paulo: Faculdade de Medicina, Universidade de São Paulo; 2010.

INTRODUÇÃO: Em pacientes com doença pulmonar obstrutiva crônica a reabilitação pulmonar tem demonstrado ser efetiva sobre diversos aspectos, incluindo a melhora física e emocional nas atividades diárias com conseqüente melhora da qualidade de vida e diminuição da dispnéia. Embora os resultados benéficos da atividade física estejam bem documentados, não se sabe, ao certo, os efeitos do exercício físico sobre a lesão pulmonar em pacientes enfisematosos. OBJETIVO: Verificar o efeito pulmonar de dois protocolos de atividade física (intensidade leve-moderada e alta), em ratos Wistar com enfisema pulmonar induzido pela administração intratraqueal de papaína. MÉTODOS: Os animais foram divididos em 5 grupos. Destes, 3 grupos receberam administração intratraqueal de solução de papaína, sendo que um deles permaneceu sedentário (PS) e os outros dois realizaram atividade física intensa (PHE) ou moderada (PME) por 10 semanas após a instalação do enfisema (40 dias após a instilação). 0 mesmo aconteceu com o grupo que recebeu solução salina ( $\mathrm{NaCl} 0,9 \%)$, sendo que um deles permaneceu sedentário (SS) e o outro realizou atividade física intensa (SHE). Foram realizadas medidas de função pulmonar, medidas morfométricas, de densidade de fibras colágenas e elásticas e avaliação imuno-histoquímica da expressão de isoprostano-8 no tecido pulmonar. RESULTADOS: Houve aumento significativo nos valores de intercepto linear médio ( $\mathrm{Lm}$ ) nos três grupos que receberam papaína, evidenciando a presença de enfisema pulmonar. O grupo PHE mostrou um aumento maior dos valores de Lm quando comparado os grupos PS e PME $(p<0,001)$. Também foram observados valores da elastância do sistema respiratório significativamente menores nos grupos que receberam instilação de solução de papaína (PS, PME e PHE), comparados aos grupos que receberam instilação de solução salina (SS e SHE) $(p<0,001)$. Os grupos que receberam solução de papaína mostraram um discreto aumento na proporção do volume de fibras colágenas quando comparados com os animais que receberam solução salina (SS e SHE) ( $p=0.049)$. CONCLUSÃO: A atividade física intensa piorou a destruição alveolar em nosso modelo de enfisema pulmonar em ratos, sem efeito no remodelamento e na função pulmonar.

Descritores: enfisema pulmonar, Doença pulmonar obstrutiva crônica, atividade física, reabilitação, ratos Wistar. 
SUMMARY 
Barnabé, V. Effects of high and mild exercise training on

pulmonary emphysema. [thesis]. São Paulo: School of Medicine, University of São Paulo; 2010.

INTRODUTION: In patients with pulmonary obstructive chronic disease the pulmonary rehabilitation has shown to be effective in several aspects, including the physical and emotional improvement in the daily activities with consequent improvement in quality of life and the decrease of dyspnea. Although the favorable results of the physical activity are well established, it is uncertain the effects of the physical activities on the pulmonary injury in patients with enphysema. OBJECTIVE: The purpose of the present study was to evaluate if physical exercise of different intensity (moderate and highintensity) have different effects on the development of protease-induced emphysema in rats. METHODS: The animals were divided in five groups. From this, three groups received intratracheal instillation of papain, being that one of them remained sedentary (PS) and the other two performed intense physical activity (PHE) or moderate (PME) for ten weeks after the installation of emphysema (40 days after the instalation). The same happened to the group that received saline solution $(\mathrm{NaCl} 0.9 \%)$, one of that remained sedentary (SS) and the other one performed intense physical activity (SHE). We performed measurements of pulmonary function, lung morphometry, density of collagen and elastic fibers and the expression of 8-isoprostane in the pulmonary issue. RESULTS: There was significant increase in the values of the mean linear intercept. There was significant increase in the values of the mean linear intercept $(\mathrm{Lm})$ in the three groups that received papaina, making evident the presence of pulmonary emphysema. The group PHE shows a major increase in the values of Lm when compared with the groups PS and PME $(p<0.001)$. We also observed significant minor elastance values of the respiratory system in the groups that received solution of papain-instilation (PS, PME e PHE), compared with the groups that received saline solution (SS e SHE) $(p<0.001)$. The groups that received papainsolution showed a discreet increase in the proportion of the value of collagen fibers when compared to the animals that received saline solution (SS e SHE) $(p=0.049)$. CONCLUSION: The intense physical activity worsens the alveolar destruction in our model of pulmonary enphysema in rats, without effect in the pulmonary remodeling and in the pulmonary function.

Keywords: pulmonary emphysema, cronic obstructive pulmonary disease, physical activity, rehabilitation, Wistar rats. 
INTRODUÇÃO 


\section{Introdução}

\subsection{DPOC}

\subsubsection{DEFINIÇÃO, PREVALÊNCIA E MORTALIDADE}

A Doença Pulmonar obstrutiva Crônica (DPOC) é definida com "uma doença capaz de ser evitada e tratada, apresentando alguns efeitos extra pulmonares significativos que podem contribuir para a sua gravidade em alguns pacientes. O componente pulmonar é caracterizado por limitação ao fluxo aéreo não totalmente reversível, geralmente progressiva e associada a uma resposta inflamatória anormal do pulmão a partículas ou gases nocivos" (Rabe et al., 2009).

A limitação ao fluxo aéreo da DPOC é causada por uma mistura entre doença de pequenas vias aéreas (bronquiolite obstrutiva) e destruição do parênquima alveolar (enfisema pulmonar) e a contribuição relativa de cada uma delas varia de indivíduo para indivíduo (Rabe et al., 2008).

A DPOC é uma das principais causas mundiais de morbidade e mortalidade e resulta em um impacto social e econômico crescente. A 
prevalência, a morbidade e a mortalidade variam entre países e entre grupos diferentes de um mesmo país, em geral relacionadas diretamente à prevalência do tabagismo. Em muitos países, a poluição do ar devido à queima de biomassa (carvão, lenha entre outros combustíveis) tem sido identificada também como importante fator de risco (Rabe et al.,2007).

A prevalência da DPOC pode variar muito em razão de diferenças nos métodos de levantamento, nos critérios de diagnóstico e nas abordagens analíticas (Halbert et al., 2006). A maioria dos dados mundiais mostra que menos de $6 \%$ da população afirma ter a doença, o que reflete 0 subreconhecimento e subdiagnóstico da DPOC (van de Boom et al., 1998). Por outro lado, estudos realizados em diversos países com métodos padronizados, incluindo parâmetros espirométricos, mostram evidências de que, em indivíduos com mais de 40 anos, a prevalência de DPOC pode chegar a cerca de 25\% (Rabe at al., 2007). No Brasil, os dados de prevalência, obtidos por meio de questionários de sintomas, estimam a DPOC em adultos com mais de 40 anos em 12\% da população segundo o II Consenso Brasileiro sobre DPOC de 2004. Na cidade de São Paulo a prevalência da DPOC varia de 6 a 15,8\% em indivíduos maiores de 40 anos. A prevalência da doença aumenta progressivamente com a idade, acompanhando a perda funcional pulmonar que ocorre em todos os indivíduos (Menezes et al. 2005). 
Dados do DATASUS* mostram que bronquite crônica e enfisema pulmonar foram responsáveis por cerca de 170.000 internações em 2007 no sistema público de saúde em todo o Brasil, representando um total de 1,5\% do total de internações em hospitais públicos (Menezes et al. 2005).

Em 1990, a DPOC ocupava o sexto lugar como causa de morte no mundo e deverá ficar em terceiro lugar em 2020 (Lopez et al., 2006). Essa mortalidade elevada está associada ao aumento do tabagismo e ao aumento na expectativa de vida da população. Em 2000, o número de mortes por DPOC nos Estados Unidos foi maior nas mulheres (59.938) com relação aos homens (59.118), porém o índice de mortalidade entre os homens é ligeiramente mais alto do que o observado nas mulheres. (Rabe et al., 2007). No Brasil, nos últimos 20 anos, vem crescendo o número de óbitos por DPOC em ambos os sexos. A DPOC apresentou taxa de mortalidade que variou de 7,88 para 19,04 em cada 100.000 habitantes nas décadas de 1980 e 1990 , passando a ocupar da $4^{a}$ para a $7^{a}$ posição entre as principais causas de morte (Jardim et al., 2004). 


\subsubsection{ETIOLOGIA, QUADRO CLÍNICO E CLASSIFICAÇÃO}

A principal causa da DPOC é o tabagismo. Entretanto, estudos epidemiológicos mostram evidências consistentes de que não fumantes também podem desenvolver obstrução crônica ao fluxo aéreo (Behrendt et al., 2005).

O fator de risco genético mais evidente é a deficiência de alfa-1 antitripsina, uma proteína responsável por mais de $90 \%$ da capacidade antiproteolítica do trato respiratório. Sua ausência provoca um desenvolvimento prematuro e acelerado de enfisema panlobular associado à diminuição da função pulmonar e que ocorre tanto em fumantes quanto em não fumantes (Rabe et al., 2009; Jardim et al., 2006).

As exposições ocupacionais incluem poeiras orgânicas e inorgânicas e agentes químicos. Estas exposições contribuem de 10 a 20\% para os sintomas e comprometimento funcional da DPOC (Balmes et al., 2003).

O ar resultante da queima de biomassa em habitações pouco ventiladas representa um fator de risco importante para o desenvolvimento a DPOC, principalmente entre mulheres em países em desenvolvimento. Existem evidências crescentes de que a poluição atmosférica também é um fator de risco importante para o desenvolvimento da DPOC, embora não 
esteja totalmente estabelecida sua real contribuição para o desenvolvimento da DPOC. Outros fatores relevantes para a predisposição da DPOC são sexo, as infecções respiratórias, o crescimento e o desenvolvimento pulmonar, o nível socioeconômico, o estado nutricional e as comorbidades (Salvi e Barnes, 2009; Rabe et al., 2007).

Os sintomas mais freqüentes encontrados nos pacientes com DPOC são: dispnéia, tosse, expectoração e fadiga. Os sintomas, além de constituírem um desfecho clínico, contribuem em outros desfechos, como tolerância ao exercício e qualidade de vida (Jardim et al., 2006).

O componente pulmonar manifesta-se inicialmente com a tosse que é o sintoma mais encontrado, pode ser diária ou intermitente e pode preceder a dispnéia ou aparecer simultaneamente a ela. O aparecimento da tosse no fumante é tão freqüente que muitos pacientes não a percebem como sintomas de doença, considerando-a como o "pigarro do fumante". A tosse produtiva ocorre em aproximadamente $50 \%$ dos fumantes. A presença de sintomas respiratórios crônicos no paciente com hábito tabágico (cigarro, cigarrilha, cachimbo, charuto) deve levar à suspeita clínica de DPOC (Jardim et al.,2004).

A dispnéia é o principal sintoma associado à incapacidade, redução da qualidade de vida e pior prognóstico. É geralmente progressiva com a evolução da doença, provocando redução progressiva das atividades do 
portador de DPOC até a incapacidade. Muitos pacientes só referem a dispnéia numa fase mais avançada da doença, pois atribuem parte da incapacidade física ao envelhecimento e à falta de condicionamento físico (ODonnell,et al.1992; Eltayara et al. 1996; Ambrosino e Scano, 2001; Calverley e Kouloris, 2005; Jardim et al. 2004; Jardim et al.,2004).

A dispnéia da DPOC é, classicamente, associada à sensação resultante do esforço gerado para contrapor o aumento da resistência das vias aéreas. Um segundo mecanismo está ligado ao aprisionamento de ar e à hiperinsuflação, com conseqüente rebaixamento do diafragma e menor eficiência da musculatura respiratória, gerando maior gasto energético e sensação de desconforto. Respostas à hipoxemia, hipercapnia e acidose são um terceiro mecanismo relatado como potencial gerador de dispnéia. Nos últimos anos, a descrição da limitação ao fluxo expiratório (LFE) e da hiperinsuflação dinâmica, como fatores fundamentais associados à dispnéia, trouxeram uma nova compreensão da fisiopatologia da DPOC (ODonnell,et al.1999; Hadcroft e Calverley, 2001; ODonnell, et al. 2001; Calverley e Kouloris, 2005).

Em uma curva fluxo-volume normal, observamos que o fluxo expiratório gerado não é máximo; aumentos da demanda ventilatória são obtidos por aumento do fluxo. A maioria dos indivíduos saudáveis não apresenta LFE mesmo durante atividades físicas intensas. Pacientes com LFE atingem seu fluxo máximo durante o volume corrente e, em 
conseqüência, para adequarem a demanda ventilatória, são obrigados a aumentar o volume pulmonar, tornando-se hiperinsuflados em repouso ou tendendo a desenvolver hiperinsuflação dinâmica aos esforços, o que reduz a tolerância ao exercício (Kouloris et al.,2007; ODonnell,et al.2001; Calverley e Kouloris, 2005; Lecture, 2000)

Embora esta resposta não seja universal, pacientes que adotam esta estratégia comprometem sua mecânica respiratória devido ao encurtamento do diafragma, que o torna menos eficiente, e pela pressão positiva expiratória final (que impõe uma carga inspiratória), gerando maior gasto energético para manter a ventilação adequada. Esse mecanismo tem sido descrito como dissociação neuromecânica, na qual o paciente necessita de um esforço inspiratório muito grande para gerar pequenas variações de volume (Ayers et al., 2001; Aliverty et al.,2004; Calverley, 2004).

A realização de atividade física está significativamente prejudicada em muitos pacientes com DPOC, alterando de maneira significativa sua qualidade de vida, visto que há comprometimento na realização das atividades de vida diária. A patogênese da limitação ao exercício é complexa e envolve perda da força dos músculos respiratórios, alterações das trocas gasosas e anormalidades na mecânica pulmonar, além de fraqueza muscular nos membros superiores e inferiores. O principal sintoma responsável por esta limitação é o desconforto respiratório (dispnéia), desencadeado quando os pacientes realizam tarefas da vida diária. Esta 
diminuição da capacidade física leva o paciente à inatividade, o que resulta em menor tolerância ao exercício, criando assim, um ciclo vicioso que evolui até que o paciente fique dependente. Como é difícil realizar medições confiáveis das atividades de vida diária dos pacientes, as medidas fisiológicas de capacidade de exercício, realizadas em laboratórios são, geralmente, utilizadas como marcadores deste desfecho (Jardim et al., 2006; Rabe et al., 2009).

O diagnóstico de DPOC é realizado com base na apresentação clínica dos sintomas e nos exames de espirometria, radiológicos e $\mathrm{pH}$, sendo a espirometria obrigatória, devendo ser realizada antes e após broncodilatador e de preferência em uma fase estável da doença. Os valores espirométricos permitem a avaliação de uma multiplicidade de parâmetros, porém os mais importantes do ponto de vista de aplicação clínica são a CVF (capacidade vital forçada), o VEF1 (volume expiratório forçado no primeiro segundo), e a relação VEF1/CVF, pois mostram menor variabilidade inter e intra-individual (Jardim et al., 2004).

A DPOC pode ser classificada, de modo simples, em quatro estágios; segundo índices espirométricos (Tabela 1), sendo as medidas de VEF1 e da relação VEF1/CVF recomendadas para o diagnóstico e avaliação da gravidade da DPOC, mas o grau de reversibilidade da obstrução pulmonar não é mais recomendado para diagnóstico ou prognóstico de resposta ao 
tratamento a longo prazo com broncodilatadores ou corticóides (Rabe et al., 2007).

TABELA 1 - Classificação espirométrica da gravidade da DPOC

\begin{tabular}{|l|l|}
\hline Estádio I - Doença leve & $\begin{array}{l}\mathrm{VEF}_{1} / \mathrm{CVF}<0,70 \\
\mathrm{VEF}_{1} \geq 80 \% \text { do previsto }\end{array}$ \\
\hline Estádio II - Moderada & $\begin{array}{l}\mathrm{VEF}_{1} / \mathrm{CVF}<0,70 \\
50 \leq \mathrm{VEF}_{1} \leq 80 \% \text { do previsto }\end{array}$ \\
\hline Estádio III - Grave & $\mathrm{VEF}_{1} / \mathrm{CVF}<0,70$ \\
& $30 \leq \mathrm{VEF} 1 \leq 50 \%$ do previsto \\
\hline Estádio IV - Muito grave & $\mathrm{VEF}_{1} / \mathrm{CVF}<0,70$ \\
& $\mathrm{VEF}_{1}<30 \%$ do previsto \\
& $\mathrm{VEF}_{1}<50 \%$ do previsto mais \\
& insuficiência respiratória \\
\hline
\end{tabular}

- baseada no VEF 1 pós brocodilatador.

\subsubsection{FISIOPATOLOGIA}

As alterações características da DPOC são encontradas no parênquima pulmonar, nas vias aéreas proximais, nas vias aéreas periféricas e na vasculatura pulmonar (Hogg, 2004). O processo inflamatório crônico causa alterações dos bronquíolos (bronquiolite obstrutiva), nos 
brônquios (bronquite crônica) e destruição do parênquima pulmonar (enfisema pulmonar) (Jardim et al., 2004).

A inflamação cursa com o aumento de células inflamatórias específicas em diferentes regiões do pulmão e alterações estruturais resultantes do processo repetido de lesão e reparo. Em geral, essas alterações inflamatórias e estruturais das vias aéreas aumentam com a gravidade da doença (Rabe et al., 2009). A inflamação nos pacientes com DPOC parece ser uma amplificação da resposta inflamatória normal do sistema respiratório a irritantes crônicos. Os mecanismos responsáveis por esta amplificação não são totalmente conhecidos podendo ser geneticamente determinados. O excesso de proteinases no pulmão e o estresse oxidativo também estão envolvidos no mecanismo de lesão inflamatória. A inflamação na DPOC envolve diferentes tipos celulares, principalmente linfócitos, neutrófilos e macrófagos (Barnes et al.,2003; Rabe et al. 2007).

O estresse oxidativo, um desequilíbrio entre oxidantes e antioxidantes, está aumentado em pacientes com DPOC, principalmente em exacerbações (Biermacki et al., 2003). A presença do estresse oxidativo tem conseqüências importantes em diversos eventos da patogênese da DPOC, como a lesão do epitélio alveolar, a hipersecreção de muco, o remodelamento da matriz extracelular (MEC) entre outros (Rahman, 2005). 
Um aspecto importante da patogênese da DPOC é o processo de remodelamento pulmonar, que afeta principalmente as pequenas vias aéreas levando as mesmas ao espessamento, fibrose e perda do acoplamento bronquíolo-alveolar e a perda do parênquima pulmonar (enfisema). O enfisema contribui para a limitação ao fluxo aéreo por meio da diminuição do recolhimento elástico e as alterações das pequenas vias aéreas aumentam a resistência ao fluxo aéreo. Estes dois componentes geralmente se apresentam em proporções variadas interagindo e contribuindo para a limitação final ao fluxo aéreo (Jeffery, 2004; Sturton et al.,2008).

Vários componentes da MEC (colágeno, fibras elásticas e proteoglicanos) podem estar envolvidos no processo de remodelamento pulmonar da DPOC. O espessamento da parede das pequenas vias aéreas é causado principalmente por fibrose envolvendo a lâmina própria, o músculo liso e a adventícia (Jeffery, 2001; Hogg et al., 2007). Estudos com animais expostos à fumaça de cigarro começaram a elucidar os mecanismos de sinalização para o processo fibrótico nas grandes e pequenas vias aéreas (Wang et al. 2003; Wang et al., 2005; Kenyon et al., 2003). Outros estudos em seres humanos demonstraram que a sinalização para o processo fibrótico está aumentada nas células epiteliais das pequenas vias aéreas de fumantes; associada a oxidantes derivados dessas células que provavelmente amplificariam a resposta para o processo fibrótico (De Bôer et al., 1998; Takizawa et al., 2001; Wang et al., 2005). 
O processo de remodelamento do enfisema pulmonar é causado principalmente pelo desequilíbrio entre as proteinases e antiproteinases, podendo ser descrito pelos seguintes eventos: 1. recrutamento de células inflamatórias para o interior dos espaços aéreos; 2. liberação pelas células inflamatórias de proteinases elastolíticas em quantidade maior do que os inibidores, causando lesões em locais específicos da MEC; 3. destruição das células estruturais do pulmão tanto em resposta a perda da MEC quanto por um evento primário e 4. reparo ineficaz de alvéolos e de fibras elásticas e, provavelmente, de outros componentes da MEC resultando em alargamento do espaços alveolares ( Shapiro, 2005).

Finlay et al. (1996) demonstraram que as fibras elásticas do septo alveolar estão alteradas, apresentando fragmentação, em indivíduos com enfisema. Estudos que avaliaram o conteúdo de colágeno no tecido pulmonar de indivíduos com DPOC demonstraram um aumento histológico e bioquímico de colágeno no parênquima alveolar de enfisematosos com alteração centrilobular (Cardoso et al., 1993; Vlahovic et al. 1999). Entretanto, os estudos que quantificaram essas fibras mostraram resultados conflitantes. Black e colaboradores (2008) demonstraram em seu estudo preservação da espessura do septo alveolar e diminuição no conteúdo de fibras elásticas no tecido pulmonar de indivíduos com DPOC quando comparados com indivíduos fumantes sem obstrução. Outro estudo demonstrou um aumento de volume nos septos alveolares com um aumento 
paralelo de fibras elásticas no tecido pulmonar de pacientes enfisematosos (Vlahovic et al. 1999).

\section{2 REABILITAÇÃO PULMONAR}

Gradativamente os pacientes com DPOC diminuem sua habilidade física e consequentemente sua qualidade de vida. A reabilitação pulmonar tem demonstrado ser efetiva na melhora da tolerância ao exercício e na melhora da qualidade de vida dos pacientes com DPOC. Tem-se visto que essas alterações afetam principalmente os DPOC em estágio moderado a grave (Guell et al., 2000; Rabe et al., 2009).

Entre os objetivos da reabilitação pulmonar destaca-se o aumento da tolerância ao exercício, aumento do metabolismo, redução do nível de dependência do paciente em relação aos cuidados médicos, melhora física e emocional nas atividades diárias com conseqüente melhora da qualidade de vida, diminuição da dispnéia, redução na ventilação, aumento no tempo de realização do teste de endurance entre outros (Rabe et al., 2009; Corso, 2000; Goldstein et al.,1994; Ribeiro et al., 1994; Neder et al., 1997). A intolerância ao exercício nos pacientes com DPOC aparece não somente pela obstrução pulmonar, mas também pela combinação de alguns fatores, entre eles mais recentemente a disfunção dos músculos esqueléticos (Serres et al., 1998; Rabe et al., 2009; Guell et al., 2000). 
Pacientes com DPOC apresentam alterações pulmonares e extrapulmonares. Dentre as alterações pulmonares observa-se o desenvolvimento ou agravamento da hiperinsuflação pulmonar dinâmica, com aprisionamento aéreo, como uma importante alteração fisiopatológica na exacerbação da DPOC. Os principais mecanismos envolvidos são: aumento da obstrução ao fluxo aéreo (causada por inflamação, hipersecreção brônquica e broncoespasmo), acompanhado de redução da retração elástica pulmonar. Todos esses fatores resultam em prolongamento da constante de tempo expiratória, ao mesmo tempo em que se eleva a freqüência respiratória como resposta ao aumento da demanda ventilatória, encurtando-se o tempo para expiração. A hiperinsuflação dinâmica gera aumento substancial da auto-PEEP ou PEEP intrínseca (PEEPi), impondo uma sobrecarga de trabalho à musculatura inspiratória para deflagração de fluxo de ar na inspiração. Por sua vez, a hiperinsuflação também compromete o desempenho muscular respiratório, modificando a conformação geométrica das fibras musculares, reduzindo a curvatura diafragmática. Além disso, nos pacientes com doença mais avançada, pode haver diminuição direta da força muscular por uso crônico de corticosteróides e desnutrição. Nas exacerbações muito graves, pode haver diminuição da resposta do comando neural (drive) no centro respiratório à hipóxia e à hipercapnia, estas decorrentes do desequilíbrio ventilação/perfusão e de hipoventilação alveolar, agravando a acidose respiratória e a hipoxemia arterial (Peigang, 2002; Riera, 2001; Orozco-Levi, 2003) 
Ainda, a destruição da arquitetura pulmonar pode alterar a disposição normal das vias aéreas, contribuindo para o aumento da resistência destas (Barnes, Shapiro, Pauwels, 2003).

Dentre as alterações extra-pulmonares, existem vários estudos demonstrando a diminuição da endurance do sistema muscular esquelético em pacientes DPOC associado às alterações da função pulmonar (Serres et al., 1998). Atrofia e fraqueza dos músculos periféricos são comuns, levando a redução da capacidade física. Alguns estudos têm verificado o efeito do treinamento em pacientes com DPOC, observando um aumento da força e do tamanho dos músculos periféricos associado à melhora do desempenho na realização da atividade física (Simpson et al., 1992; Clark et al., 2000; Bernard et al., 1999).

A reabilitação pulmonar visa primariamente o treino aeróbico, melhorando clinica e significativamente a capacidade do exercício submáximo e secundariamente a melhora psicológica (Laçasse, 2002; Casaburi,1993). A melhora da capacidade das enzimas oxidativas, a bioenergética celular e a redução da fadiga têm sido demonstradas no músculo quadríceps em pacientes DPOC, após a reabilitação pulmonar (Mador et al., 2004). 
Além da melhora da capacidade física, a reabilitação pulmonar precoce diminui o tempo e o número de vezes em que o paciente é hospitalizado. Uma meta-análise de Puhan, 2005 demonstrou que pacientes com DPOC se beneficiam da reabilitação pulmonar após uma exacerbação; com melhora da capacidade física, da qualidade de vida e redução da mortalidade (Osthoff and Leuppi, 2010).

Desde 1990 é realizado grande esforço para desenvolver um protocolo tolerável, porém efetivo aos pacientes DPOC. Ainda assim, não se chegou a um consenso sobre o tipo de atividade física mais eficiente para os pacientes DPOC e sobre o tipo de exercício. Ainda não sabemos o quanto o exercício contínuo é mais efetivo do que os protocolos de exercício com intervalos, sobre a qualidade de vida e a capacidade física (Puhan et al., 2008).

\subsubsection{ATIVIDADE FISICA AERÓBICA}

A atividade física aeróbica realizada regular e sistematicamente desencadeia uma série de adaptações crônicas, tais como: aumento do consumo máximo de oxigênio (McArdle et al., 1998; Denadai, 1999), aumento da densidade óssea e da massa muscular (McArdle et al., 1998), melhora da resposta imunológica (se a atividade for predominantemente de intensidade leve e moderada) (Pedersen, 2000), entre outras. 
O exercício ainda aumenta a resistência ao estresse oxidativo, proporcionando uma maior proteção (Pedersen e Hoffman, 2000; Radak et al., 2002). Estudos epidemiológicos têm demonstrado que o exercício diminui a incidência de doenças associadas ao estresse oxidativo (Radak et al., 2008).

Agudamente, o exercício aumenta o estresse oxidativo, produzindo um ambiente pró-oxidante (Li et al., 2002). Quando o exercício é repetido, o corpo se adapta a esse estresse de tal forma que ele possa agir rapidamente, para que o estresse oxidativo possa ser eliminado ou reduzido antes que provoque danos à estrutura celular. Assim, as adaptações a um exercício regular parecem ter uma proteção antioxidante (Radak e Chung, 2005).

Outro efeito importante da atividade física é seu efeito antiinflamatório. Há um consenso na literatura de que a atividade aeróbica de alta intensidade e longa duração desencadeiam uma resposta pró-inflamatória, enquanto atividades de intensidade leve e moderada associadas à média e longa duração desencadeiam uma resposta antiinflamatória (Petersen e Pedersen, 2005; Moldoveanu et al. 2001; Zieker et al., 2005). A atividade física aeróbica é capaz de modular tanto o sistema imune inato quanto o adaptativo (Costa Rosa e Vaisberg, 2002). 
Normalmente ocorrem duas respostas ao exercício, a resposta aguda e a adaptação crônica (Costa Rosa e Vaisberg, 2002; Cannon et al., 1991; Lakier, 2003). A resposta aguda é uma reação transitória ao estresse, enquanto o estímulo crônico gera uma resposta de adaptação crônica ao estresse; o que permite ao organismo tolerar de maneira mais adequada o exercício (Costa Rosa e Vaisberg, 2002).

Embora os resultados benéficos da atividade física estejam bem documentados (Lacasse et al., 2003; Lacasse et al.,1996), não se sabe, ao certo, os efeitos do exercício físico sobre a lesão pulmonar em pacientes enfisematosos. Ainda existem muitas dúvidas sobre qual a melhor forma de se fazer e se existe impacto a Reabilitação Respiratória na evolução da DPOC e na freqüência de suas complicações.

Há necessidade de mais estudos clínicos, com desenho experimental adequado, para melhor estabelecer, em pacientes com DPOC, o papel da Reabilitação Respiratória e de seus componentes, incluindo o tipo de atividade física, sua duração e intensidade. 
Estudos em modelos experimentais de DPOC também são relevantes, uma vez que através deles é possível estudar parâmetros prédeterminados de maneira controlada e em grupos mais homogêneos.

\subsubsection{MODELOS EXPERIMENTAIS DE DPOC}

Os animais têm sido amplamente utilizados em modelos experimentais e ainda na observação da evolução de doenças que os acometem (Slauson, 1980; Mc Pherson, 1978). Os estudos empregando modelos animais de enfisema pulmonar têm servido como importante ferramenta nas últimas décadas, pois permitiram esclarecimentos sobre as respostas celulares, anatômicas e bioquímicas dos pulmões a uma série de injúrias e alterações genéticas.

O primeiro trabalho publicado na área de enfisema em modelo experimental foi o de Gross et al. (1965), onde os animais receberam instilação intratraqueal de papaína e apresentaram enfisema centrilobular. Após este trabalho, vários outros grupos desenvolveram trabalhos experimentais com enfisema pulmonar e instilação intratraqueal de papaína. 
Atualmente os modelos mais utilizados para indução de enfisema em animais são:

- Instilação de proteases;

- Inalação de gases tóxicos (ex. dióxido de nitrogênio e fumaça de cigarro);

- Animais modificados geneticamente.

Nos modelos de degradação tecidual são utilizadas enzimas elastolíticas, capazes de degradar o tecido pulmonar levando a um quadro de enfisema pulmonar; proteinases como elastase neutrofílica de humanos, elastase pancreática de suínos ou papaína induzem um enfisema panacinar após uma única instilação intratraqueal (Snider,1986; Snider,1992). São modelos nos quais podemos observar anormalidades da função pulmonar, hipoxemia e metaplasia de células secretoras que são características encontradas em células secretoras (Groneberg e Chung, 2004).

Inicialmente o mecanismo de enfisema induzido pela administração intratraqueal de elastase leva a uma perda de fibras de colágeno e elastina. Tardiamente os níveis de elastina tendem a apresentar valores normais, mas observa-se um aumento de fibras colágenas. A matriz extracelular apresenta-se com uma estrutura reduzida e com uma estrutura anormal das vias aéreas (Kuhn et al., 1976). Juntamente a esses eventos ocorre um 
processo inflamatório que transforma o alargamento dos espaços alveolares em lesões similares às encontradas em enfisematosos. Portanto a progressão da doença deve-se, em grande parte, aos efeitos destrutivos exercidos pelas proteinases inflamatórias (Groneberg e Chung, 2004).

O modelo experimental de fumaça de cigarro para indução de enfisema pulmonar é bastante utilizado e apresenta resultados consistentes quanto ao aparecimento de enfisema, de remodelamento de vias aéreas e inflamação crônica, sendo considerado o modelo mais próximo da doença humana uma vez que esta é a principal substância tóxica causadora de DPOC em seres humanos (Groneberg e Chung, 2004). Porém, a utilização de enzimas elastolíticas está muito bem estabelecida com a vantagem de ter um custo menor e o tempo de instalação do enfisema ser mais rápido, cerca de 35 a 40 dias, enquanto que a fumaça de cigarro leva 6 meses para a instalação de enfisema pulmonar bem caracterizado.

Alterações genéticas monogênicas e poligênicas para mimetizar a DPOC têm apresentado amplo desenvolvimento nos últimos anos, utilizando técnicas modernas de biologia molecular (Shapiro, 2000). Animais geneticamente modificados são expostos a estímulos exógenos tóxicos, como por exemplo, fumaça de cigarro, permitindo identificar os mecanismos moleculares envolvidos na patogênese da DPOC. A combinação de animais modificados geneticamente com protocolos de inalação de agentes tóxicos 
pode ajudar na identificação de mediadores protetores ou pró-inflamatórios da DPOC (Groneberg e Chung, 2004).

Nos laboratórios de investigação médica LIM-05 (Poluição Atmosférica Experimental), LIM-61 (Cirurgia torácica) e LIM-20 (Terapêutica Experimental) foram realizados diversos trabalhos com modelos experimentais de enfisema pulmonar em ratos, sendo o modelo de indução de enfisema por administração intratraqueal de papaína padronizado. Foi observado, após 40 dias da instilação de papaína, que o enfisema pulmonar estava estabelecido e bem caracterizado do ponto de vista anatomopatológico.

Sahebjami e Vassallo (1976) realizaram um estudo com o propósito de determinar se o estresse mecânico, induzido pela atividade física, poderia influenciar o recolhimento elástico de ratos enfisematosos e ainda, como o estresse mecânico poderia explicar o processo de destruição contínuo do enfisema induzido por papaína. Observaram que o estresse da atividade física levou a uma maior destruição dos componentes elásticos do pulmão de ratos enfisematosos, piorando o enfisema pulmonar.

Martorana et al. (1979) verificaram, por meio de métodos morfométricos, se a atividade física poderia contribuir para a piora do 
enfisema pulmonar, induzido pela elastase, em hamsters. Observaram que, após 35 dias da administração de elastase, o enfisema pulmonar já estava instalado, porém sem diferença entre os grupos enfisematosos que permaneciam em repouso quando comparados aos que realizavam atividade física. Concluíram que a atividade física não piorou a progressão do enfisema pulmonar neste modelo animal.

Em 2006, Fló et al. desenvolveram em nosso laboratório (LIM-20) um estudo, verificando os efeitos da atividade física durante o desenvolvimento do enfisema pulmonar, induzido por papaína, em ratos. Os animais foram divididos em grupos, recebendo instilação intratraqueal de papaína ou veículo e foram submetidos ou não ao protocolo de atividade física intensa, imediatamente após a instilação de papaína. Após 9 semanas de atividade física foi observado um aumento do intercepto linear médio (Lm) significativo nos animais que receberam instilação intratraqueal de papaína e foram submetidos à atividade física intensa, quando comparados aos animais que foram instilados com papaína, mas não foram submetidos à atividade física. Houve, portanto, uma maior destruição do parênquima alveolar no enfisema ainda em desenvolvimento, nos animais que realizaram atividade física intensa.

Este estudo gerou várias perguntas, como:

- O mesmo aconteceria se o enfisema já estivesse instalado? 
- Se os animais fossem submetidos a diferentes intensidades de atividade física, a resposta à destruição alveolar seria a mesma?

Considerando a importância epidemiológica e social da doença pulmonar obstrutiva crônica e a necessidade de estudar, com mais detalhe, o efeito da atividade física sobre a evolução do enfisema pulmonar já instalado, o presente estudo se propôs a avaliar diferentes intensidades de atividade física (leve-moderada e intensa) e seus efeitos no pulmão de ratos Wistar com enfisema.

Não encontramos, até o momento, em revisão bibliográfica, estudos em que a atividade física de diferentes intensidades tenha sido utilizada, em animais de laboratório, para verificar as possíveis alterações no enfisema pulmonar.

Consideramos este estudo relevante para os programas de reabilitação pulmonar em pacientes com DPOC, pela importância nas recomendações de intensidade e freqüência, ainda não estabelecidas, com as quais estes pacientes deveriam realizar a atividade física. 
OBJETIVOS 
2.OBJETIVOS

O objetivo deste estudo foi:

- Verificar o efeito pulmonar de dois protocolos de atividade física (intensidade leve-moderada e alta), em ratos Wistar com enfisema pulmonar induzido pela administração intratraqueal de papaína. 
MÉTODOS 


\section{MÉTODOS}

Este estudo foi aprovado pelo comitê de Ética para Análise de Projetos de Pesquisa do Hospital das Clínicas da Faculdade de Medicina da Universidade de São Paulo (CAPPesq - HCFMUSP), sob o protocolo $\mathrm{n}^{\circ}$ 090/05. Os animais foram manejados de acordo com a orientação para cuidados com animais de laboratório, publicados pelo National Institutes for Health (publicação 86-23, revisada em 1985).

Utilizamos 40 ratos Wistar, adultos jovens, fornecidos pelo Biotério da Faculdade de Medicina da Universidade de São Paulo. Os animais tinham idade de 8 semanas e pesavam $294 \pm 23$ g (média \pm SD), foram mantidos em condições controladas de temperatura $\left(22-25^{\circ} \mathrm{C}\right)$ e luminosidade $(12 \mathrm{~h}$ claro/12h escuro), e $70 \%$ de umidade relativa. A alimentação constou de água e ração "ad libitum”.

\subsection{PROTOCOLO EXPERIMENTAL}

Durante o período do protocolo experimental, os animais foram mantidos em gaiolas próprias, em biotério de manutenção. Foram levados ao laboratório cinco dias por semana para realização da atividade física, por um período de dez semanas. 


\subsection{INDUÇÃO DO ENFISEMA}

Os animais foram submetidos à sedação com éter etílico (Merck, Brasil) e anestesiados com isoflurano (Baxter Healthcare, Porto Rico) a 1\%, diluído em $100 \%$ de oxigênio a um fluxo de $2 \mathrm{l} / \mathrm{min}$. Foi utilizado um nebulizador de gases Isovapor (1224K, Takaoka, Brasil). Após a anestesia, foi introduzida uma cânula de polietileno de $2 \mathrm{~mm}$ de diâmetro e $7 \mathrm{~cm}$ de extensão na traquéia dos animais, por meio de um laringoscópio pediátrico com lâmina adaptada a pequenos animais. A cânula foi, então, conectada a um aparelho de ventilação mecânica para pequenos animais (flexiVent, Scireq, Canadá) com volume corrente de $10 \mathrm{~mL} / \mathrm{Kg}$ e freqüência respiratória de 90 ciclos por minuto.

O enfisema foi induzido por instilação intratraqueal de dose única de papaína, 10-20 miligramas de papaína (10-20 U/mg proteína, Valdequímica Produtos Químicos - Brasil), dissolvida em $1 \mathrm{~mL}$ de solução salina ( $\mathrm{NaCl}$ 0,9\%) por meio da cânula endotraqueal.

O grupo controle foi submetido à instilação intratraqueal de $1 \mathrm{~mL}$ de solução salina.

Todos os grupos permaneceram 40 dias no biotério para manutenção, para instalação do enfisema, segundo protocolo de Shapiro, 2000. 


\subsection{GRUPOS EXPERIMENTAIS}

Os animais foram divididos da seguinte forma:

- Grupo papaína-exercício-intenso (PHE): composto por 10 animais que receberam administração intratraqueal de solução de papaína, para indução de enfisema pulmonar e posteriormente foram submetidos ao exercício físico intenso durante 10 semanas.

- Grupo papaína-exercício-moderado (PME): composto por 10 animais que receberam administração intratraqueal de solução de papaína, para indução de enfisema pulmonar e posteriormente foram submetidos ao exercício físico leve-moderado durante 10 semanas.

- Grupo papaína-sedentário (PS): composto por 10 animais que receberam administração intratraqueal de solução de papaína, para indução de enfisema pulmonar e posteriormente foram mantidos sedentários, sem realizar exercício físico, durante 10 semanas.

- Grupo Salina-exercício-intenso (SHE): composto por 10 animais que receberam administração intratraqueal de solução salina $(\mathrm{NaCl} 0,9 \%)$ e posteriormente foram submetidos ao exercício físico intenso durante 10 semanas. 
- Grupo Salina-sedentário (SS): composto por 10 animais que receberam administração intratraqueal de solução salina $(\mathrm{NaCl} 0,9 \%)$ e posteriormente foram mantidos sedentários, sem realizar exercício físico, durante 10 semanas.

\subsection{TREINAMENTO FÍSICO}

Após os 40 dias da instilação de solução de papaína ou de solução salina, os grupos PHE, PME e SHE foram submetidos a um programa de exercícios em uma esteira ergométrica (Inbramed KT 4000) (Figuras 1A e 1B), adaptada para condicionamento físico de ratos, com velocidade regulável.

A esteira possui 8 baias de acrílico (10 x $10 \times 50 \mathrm{~cm}$ cada), para treinamento de 8 animais ao mesmo tempo. Cada baia possui uma tampa de acrílico com a parte anterior escura e a parte posterior transparente. Dessa maneira no início do movimento da esteira os ratos tendem a caminhar em direção à área anterior escura. 
(A)

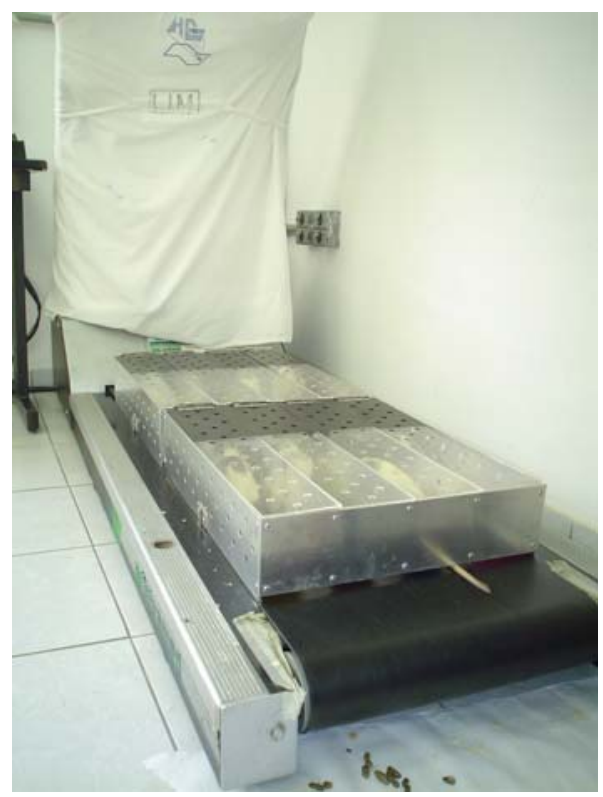

(B)

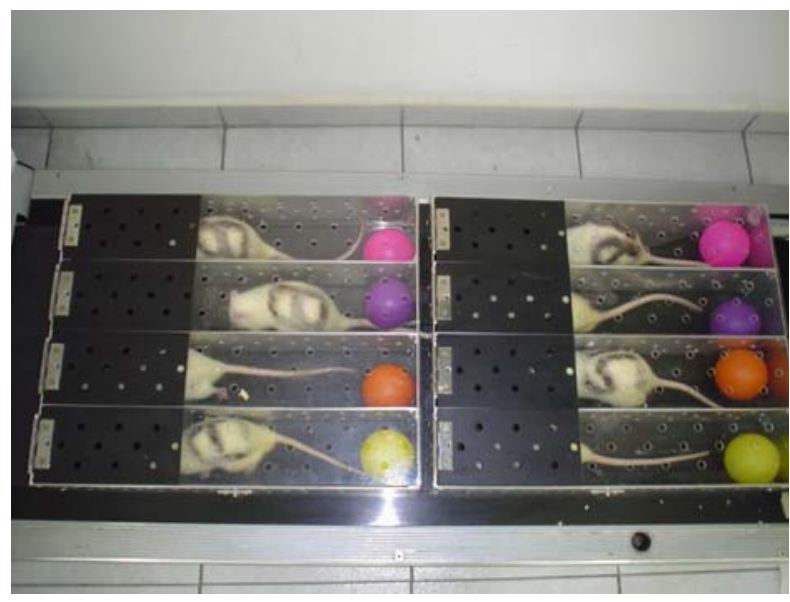

Figura 1 - (A) Foto da esteira ergométrica adaptada para ratos, (B) Foto das baias com os ratos em treinamento.

$\mathrm{Na}$ semana anterior ao início do treinamento, os animais foram submetidos a 3 dias de adaptação na esteira ergométrica, com velocidade de $0,3 \mathrm{Km} / \mathrm{h}$ por 10 minutos. Quarenta e oito horas após o terceiro dia de adaptação, os animais foram submetidos a um teste de esforço máximo. O teste teve inicio com uma velocidade de $0,3 \mathrm{Km} / \mathrm{h}$ e que era aumentada em $0,1 \mathrm{~km} / \mathrm{h}$ a cada 1,5 minutos até a exaustão dos animais. As intensidades de treinamento dos protocolos (leve-moderado e intenso) foram baseadas e adaptadas segundo a literatura.

O treinamento foi realizado uma vez ao dia, 5 dias por semana, durante 10 semanas, entre 17 e 19 horas para coincidir com o início das 
atividades dos animais, que têm hábitos noturnos, uma vez que, no biotério de manutenção utilizado, não há inversão dia/noite.

\subsection{PROTOCOLO DE TREINAMENTO FÍSICO}

O protocolo de atividade física de intensidade leve-moderada foi baseado em Navarro et al. (2003) e Hashimoto et al. (2004). Nas primeiras quatro semanas os animais eram exercitados na velocidade de $0.3 \mathrm{~km} / \mathrm{h}$, sendo aumentado gradualmente o tempo de exercício de 15 a 40 minutos. No início da quinta semana, a velocidade começava a ser aumentada gradualmente de $0.4 \mathrm{~km} / \mathrm{h}$ (quinta semana) a $0.6 \mathrm{~km} / \mathrm{h}$ (décima semana) e o tempo aumentado gradualmente de 40 para 60 minutos (Tabela 2).

O protocolo de atividade física intensa foi baseado em Vrabas et al. (1999) e Zonderland et al. (1999). Nas primeiras quatro semanas os animais eram exercitados na velocidade de $0.3 \mathrm{~km} / \mathrm{h}$, sendo aumentado o tempo de exercício gradualmente de 15 para 40 minutos. No início da quinta semana a velocidade começava a ser aumentada gradualmente de $0.4 \mathrm{~km} / \mathrm{h}$ (quinta semana) a $0.9 \mathrm{~km} / \mathrm{h}$ (décima semana) e o tempo aumentado gradualmente de 40 para 60 minutos. (Tabela 3 ). 


\begin{tabular}{|c|c|c|}
\hline $\begin{array}{c}\quad \text { Exercício } \\
\text { Leve-Moderad }\end{array}$ & $1^{\mathrm{a}}$ a $4^{\mathrm{a}}$ semana & $5^{a}$ a $10^{a}$ semana \\
\hline Tempo & $15-40 \mathrm{~min}$. & $40-60 \mathrm{~min}$. \\
\hline Velocidade & $0,3 \mathrm{~km} / \mathrm{h}$ & $0,4-0,6 \mathrm{~km} / \mathrm{h}$ \\
\hline
\end{tabular}

Tabela 2 - Protocolo de atividade física leve-moderada baseado em Navarro et al (2003) and Hashimoto et al (2004).

\begin{tabular}{|l|c|c|}
\cline { 2 - 3 } \multicolumn{1}{l|}{ Exercício Intenso } & $1^{\mathrm{a}}$ a $4^{\mathrm{a}}$ semana & $5^{\mathrm{a}}$ a $10^{\mathrm{a}}$ semana \\
\hline Tempo & $15-40 \mathrm{~min}$. & $40-60 \mathrm{~min}$. \\
\hline Velocidade & $0,3 \mathrm{~km} / \mathrm{h}$ & $0,4-0,9 \mathrm{~km} / \mathrm{h}$ \\
\hline
\end{tabular}

Tabela 3 - Protocolo de atividade física leve-moderada baseado em Vrabas et al., 1999; Zonderland et al., 1999.

\subsection{AVALIAÇÃO DA MECÂNICA PULMONAR}

Após quarenta e oito horas da última sessão de treinamento, os animais de cada grupo foram anestesiados com Thiopental $(50 \mathrm{mg} / \mathrm{kg})$, traqueostomizados e conectados a um sistema para medida de mecânica pulmonar em pequenos animais (flexiVent, Scireq, Canada) (Figura 2) e ventilados com um volume corrente de $10 \mathrm{~mL} / \mathrm{Kg}$ e frequência respiratória de 
90 ciclos/minuto. Foi utilizado uma pressão expiratória final (PEEP) de 5 $\mathrm{cmH}_{2} \mathrm{O}$, conectada à válvula expiratória do ventilador.

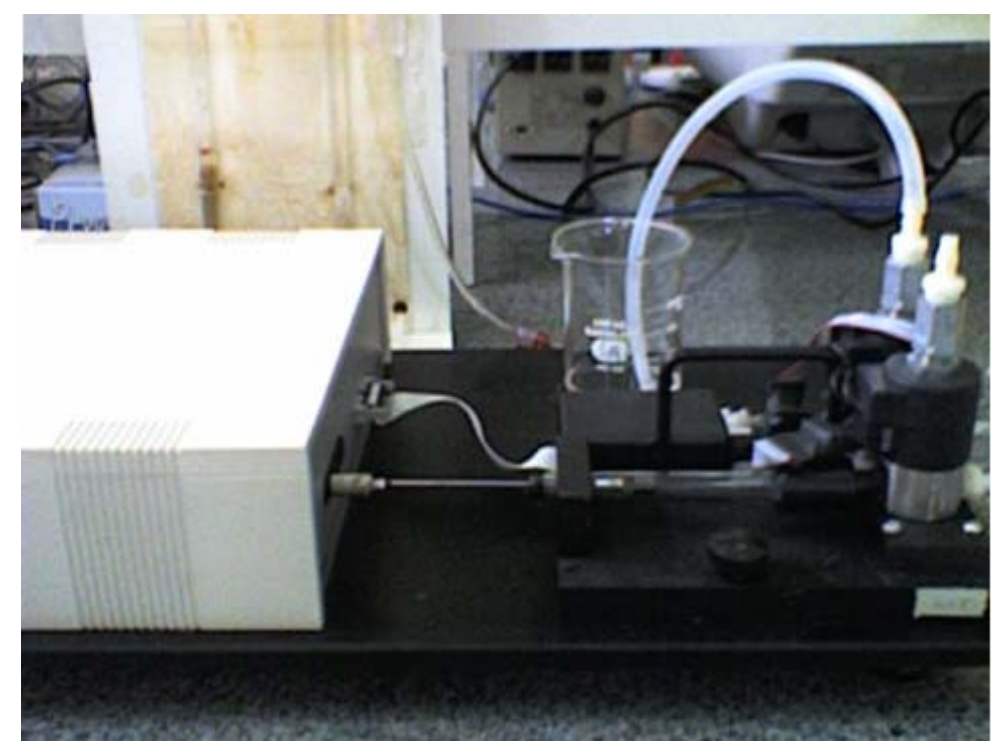

Figura 2. Sistema para medida de mecânica pulmonar em pequenos animais - Flexivent.

Para o cálculo das medidas de Rrs (resistência do sistema respiratório) e Ers (elastância do sistema respiratório), foi utilizada a equação de movimento do sistema respiratório, que se segue:

$$
\operatorname{Ptr}(t)=\text { Ers.V }(t)+\text { Rrs. V' }(t)+P_{0}
$$

Onde Ptr é a pressão traqueal, V' é o fluxo, V é o volume, t é o tempo e $\mathrm{P}_{\mathrm{o}}$ é a constante de correção de erros da capacidade residual funcional (Wagers et al., 2002). 


\subsection{AVALIAÇÃO MORFOMÉTRICA}

Após o término da avaliação da mecânica pulmonar, ainda sob anestesia geral, os animais foram sacrificados por exsanguinação (secção da aorta abdominal).

Os pulmões foram retirados, fixados e preenchidos com solução de formaldeído a $10 \%$ por $24 \mathrm{~h}$, sob uma pressão constante de $25 \mathrm{cmH}_{2} \mathrm{O}$, para homogeneizar a distensão do parênquima pulmonar.

Vinte e quatro horas após o início da fixação, os pulmões foram retirados do reservatório, cortados e submetidos a processamento histológico de rotina.

As lâminas foram coradas com Hematoxilina-eosina, Resorcinafuccina (para análise de fibras elásticas), Picrossirius (para análise de fibras colágenas) e também foram preparadas sem corantes para a realização posterior de imuno-histoquímica. 


\subsection{INTERCEPTO LINEAR MÉDIO}

O intercepto linear médio (Lm), que é uma medida do grau de distensão dos espaços aéreos distais (Margraf, 1991), foi medido utilizandose um retículo de 50 retas e 100 pontos, com área conhecida $\left(10^{4} \mu \mathrm{m}^{2}\right.$ de área total), adaptado à ocular de um microscópio. A quantificação do intercepto linear médio foi obtida pela determinação do número de vezes que estruturas do parênquima de troca gasosa interceptaram as retas. Contamos o número de intersecções entre o parênquima pulmonar e as retas da ocular, em 20 diferentes campos por animal, em cada lobo pulmonar, no aumento de 200 vezes e os resultados foram expressos em micrometros (Figura 3).
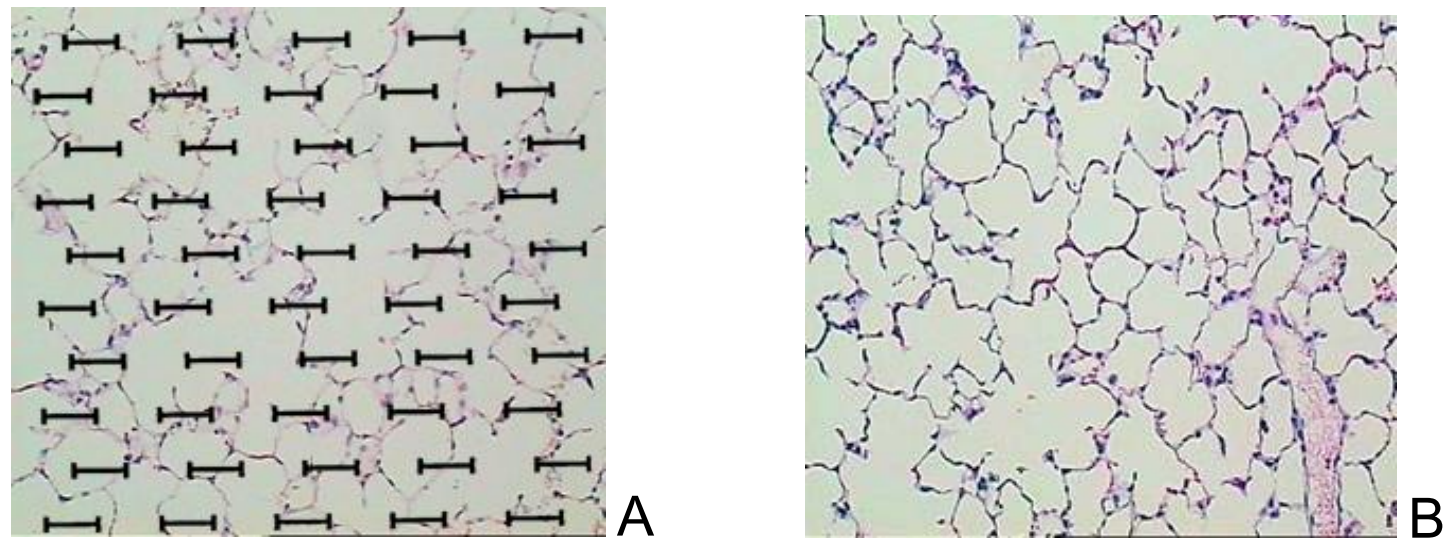

Figura 3. Demonstração do método de morfometria utilizado. A: micrografia de uma fatia de tecido pulmonar com sobreposição do retículo utilizado para quantificação do diâmetro alveolar médio (aumento de 200X). B. micrografia de uma fatia de tecido pulmonar sem sobreposição do retículo. 


\subsection{MENSURAÇÃO DE FIBRAS COLÁGENAS E ELÁSTICAS NO PARÊNQUIMA PULMONAR}

Para avaliação das fibras colágenas do parênquima pulmonar foi utilizado sistema de análise de imagem por meio do software Image Pro Plus 4.0 ( $\mathrm{NIH}$, Maryland, EUA). A análise das fibras foi realizada em um microscópio acoplado a uma câmara Nikon, ligada a um computador, com aumento de 400 vezes. Fotografamos 20 campos de parênquima pulmonar por animal, corado para fibras colágenas (Picrossírius) e elásticas (Resorcina-fucsina).

A proporção de fibras colágenas e elásticas no parênquima pulmonar foi expressa na relação entre a área total do tecido pulmonar, da imagem escolhida, e a área de fibras colágenas ou elásticas ( $\mu \mathrm{m} 2)$ da imagem (Prado, 2006). Para cada imagem foram coletadas: 1) a área total da imagem; 2) a área positiva para a marcação do septo alveolar com base no padrão estabelecido e 3) a área em branco. A subtração do item 1 pelo item 3 fornece o valor da área do septo alveolar. A porcentagem da área positiva para a marcação do septo alveolar é igual ao item 2 × 100 / área do septo alveolar.

Obtivemos, assim, a medida da proporção de fibras elásticas e colágenas por área de parênquima pulmonar, para todos os grupos. 


\subsection{IMUNO-HISTOQUÍMICA}

Para a análise imuno-histoquímica as lâminas previamente preparadas com 3 aminopropil-trietoxicilano (Silane-Sigma), contendo os cortes histológicos dos pulmões foram inicialmente desparafinadas e hidratadas. Posteriormente foram submetidas à recuperação antigênica por meio de proteinase $\mathrm{K}$ por 20 minutos $\left(37^{\circ}\right.$ Celsius) seguidos de 20 minutos de descanso. Após este período as lâminas foram lavadas em PBL.

Foi realizado o bloqueio da peroxidase endógena com água oxigenada $\left(\mathrm{H}_{2} \mathrm{O}_{2}\right)$ 10V $3 \%$ (3 x 10 minutos), seguido de incubação com o anticorpo primário: Isoprostano (IS-20; Oxford Biomedical), o qual foi aplicado aos cortes relativos ao experimento e também aos controles. As lâminas foram incubadas "overnight".

\subsection{ANÁLISE ESTATÍSTICA}

Os dados foram analisados por meio do software Sigma Stat (SPSS Inc., Chicago, IL). Todos os valores foram expressos em média e desvio padrão.

Foi utilizado Teste t-studentt (t-test) para comparação dos valores iniciais e finais de peso para cada um dos grupos. Para análise da elastância 
e proporção de fibras colágenas foi utilizada a análise de variância de um fator one way (ANOVA) seguida do teste de múltiplas comparações (HolmSidak). Para os valores de Lm foi utilizada a análise de variância one way (ANOVA) seguida do método de Dunn's para múltiplas comparações. Para a análise da resistência e análise dos dados da expressão de Isoprostano-8 foi utilizada a análise de variância de um fator one way (ANOVA). Um valor de $p$ menor que 0,05 foi considerado estatisticamente significativo. 
RESULTADOS 


\section{RESULTADOS}

\subsection{PESO CORPÓREO DOS ANIMAIS}

A Figura 4 mostra os valores do peso corporal $( \pm \mathrm{DP})$ medidos antes do início do protocolo experimental e ao final do protocolo. Houve um aumento significativo do peso corporal de todos os grupos, comparando-se cada grupo no momento inicial do protocolo (tempo 0) e no final do protocolo experimental, após 10 semanas $(p=0,001)$. Não foi observada diferença estatisticamente significativa entre os cinco grupos experimentais, tanto no momento inicial (tempo 0) e como no final do protocolo experimental. 


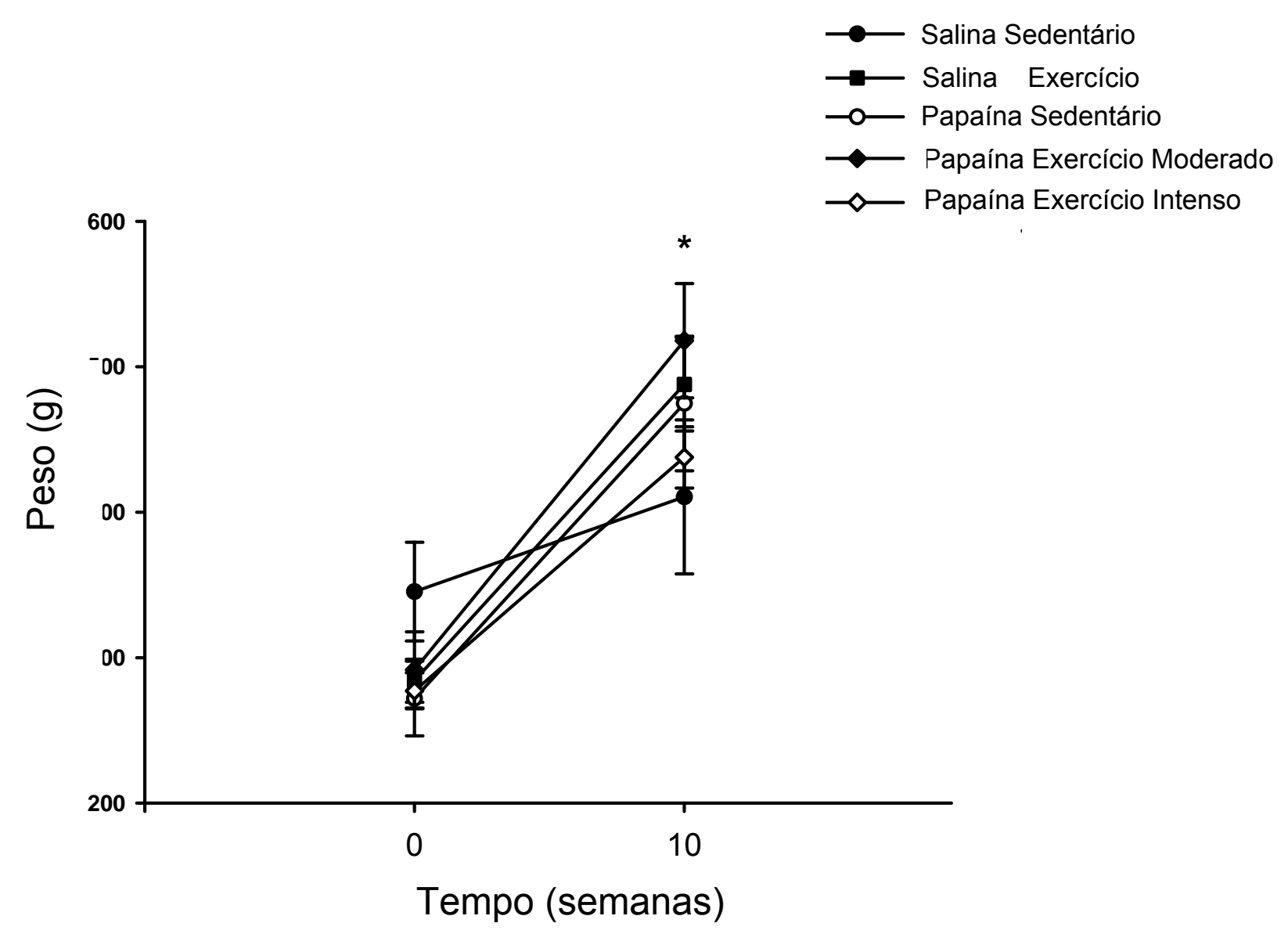

Figura 4. Peso corpóreo dos animais ao início do protocolo experimental e ao final, apresentando diferença significativa quando comparados os grupos no momento inicial e final com $p=0,001$.

\subsection{MECÂNICA RESPIRATÓRIA}

As Figuras 5 e 6 mostram, respectivamente, os valores de resistência (Rrs) e elastância (Ers) do sistema respiratório, nos 5 grupos: salina sedentário (SS), salina exercício intenso (SHE), papaína sedentário (PS), papaína exercício intenso (PHE) e papaína exercício moderado (PME). As 
medidas de mecânica respiratória foram obtidas antes do início do protocolo experimental e ao final do protocolo de atividade física de 10 semanas.

Não foi observada diferença significativa dos valores de resistência (Rrs) quando comparados os grupos no momento inicial e ao final do protocolo, assim como não foi observada diferença significativa entre os grupos, nos momentos inicial e final.

Com relação à elastância, ao final do protocolo experimental, observamos valores de Ers significativamente menores nos grupos que receberam instilação de solução de papaína (PS, PME e PHE), comparados aos grupos que receberam instilação de solução salina (SS e SHE) ( $p<$ 0,001). Houve ainda diferença estatisticamente significativa entre os valores iniciais e os valores finais de elastância em todos os grupos ( $p<0,05)$, com exceção do grupo salina exercício intenso (SHE). 


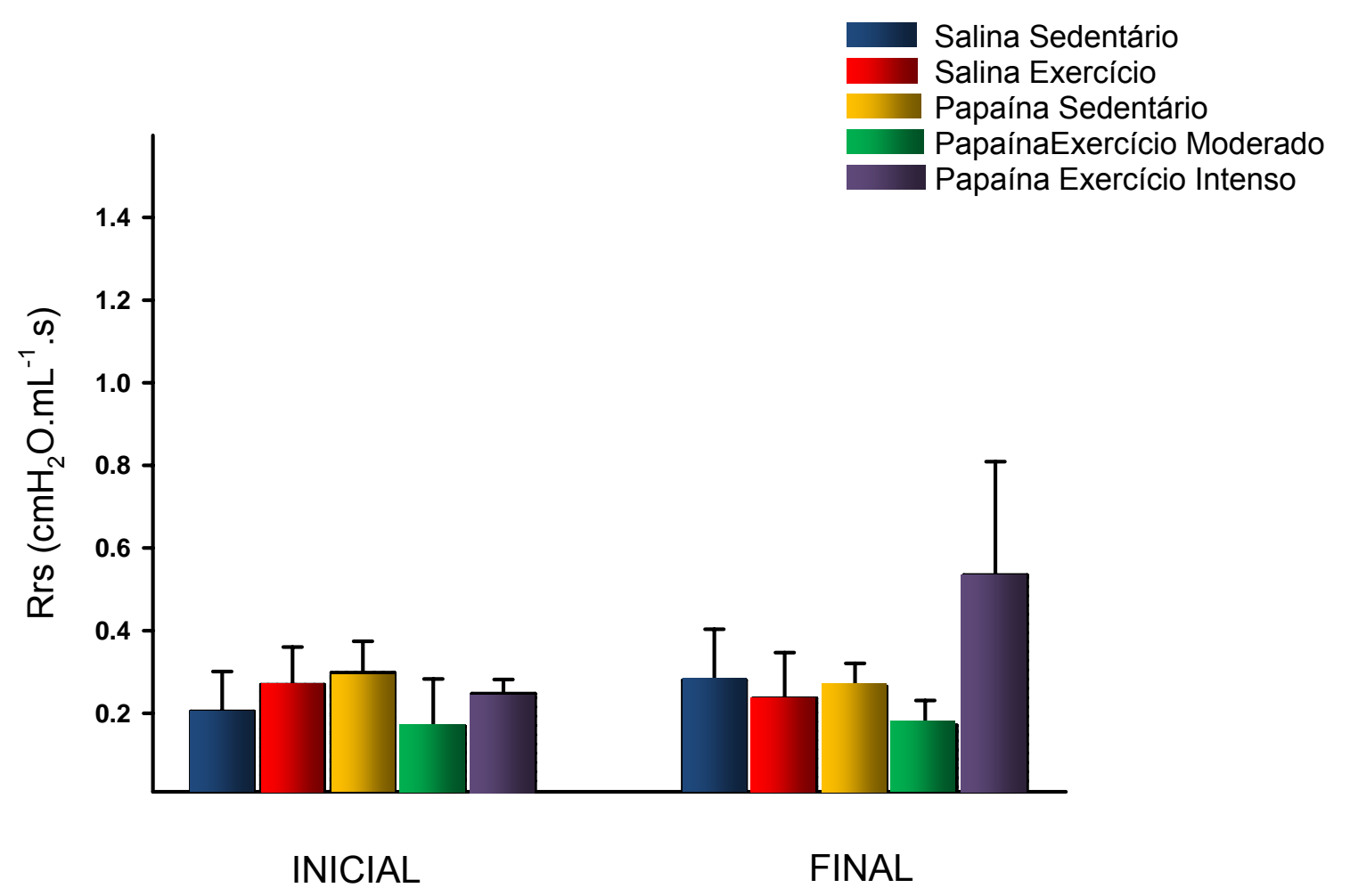

Figura 5. Resistência do sistema respiratório (Rrs) inicial e final. Não houve diferença estatisticamente significativa quando comparados o momento inicial e o final de cada grupo e quando os valores de Rrs entre os grupos, no mesmo momento, foram comparados. 


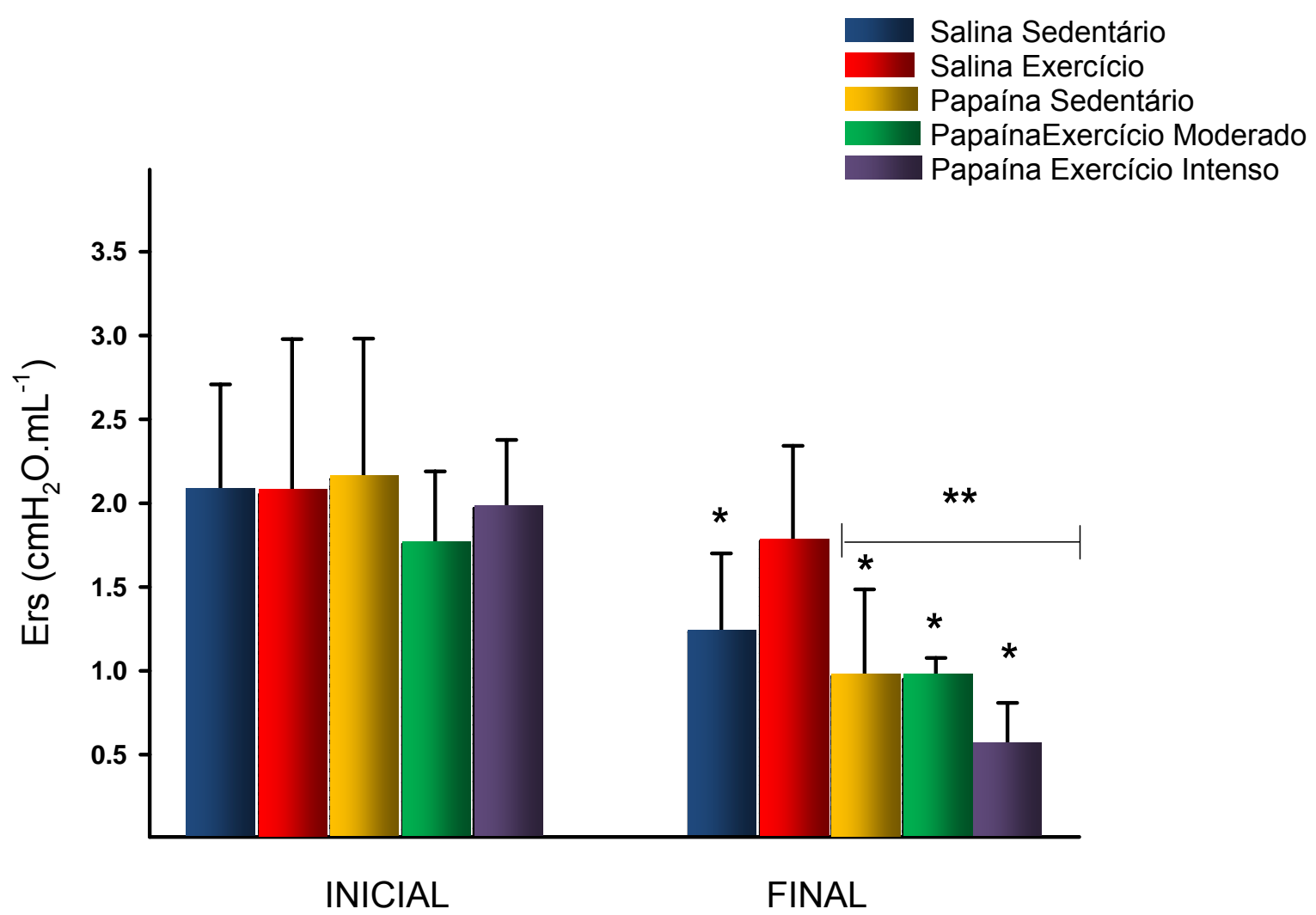

Figura 6. Valores da elastância do sistema respiratório (Ers) inicial e final nos cinco grupos experimentais. ${ }^{*} p<0,001$ comparado ao valor inicial; ${ }^{* *} p<$ 0,05 quando os grupos PS, PME e PHE aos grupos salina (SS e SHE). 


\subsection{INTERCEPTO LINEAR MÉDIO}

A análise do intercepto linear médio ( $\mathrm{Lm})$, que é uma medida dos espaços aéreos, mostra que os grupos que receberam instilação intratraqueal de papaína (PS, PME e PHE) obtiveram valores médios de Lm significativamente mais elevados $(p<0,001)$, quando comparados com os grupos que receberam instilação de salina (SS e SE) (Figura 7). O grupo PHE mostrou um aumento maior dos valores de Lm quando comparado aos grupos PS e PME $(p<0,001)$ e não foi observada diferença significativa entre os grupos PS e PME ( $p=0,239)$. 
Salina Sedentário

Salina Exercício

Papaína Sedentário

PapaínaExercício Moderado

Papaína Exercício Intenso

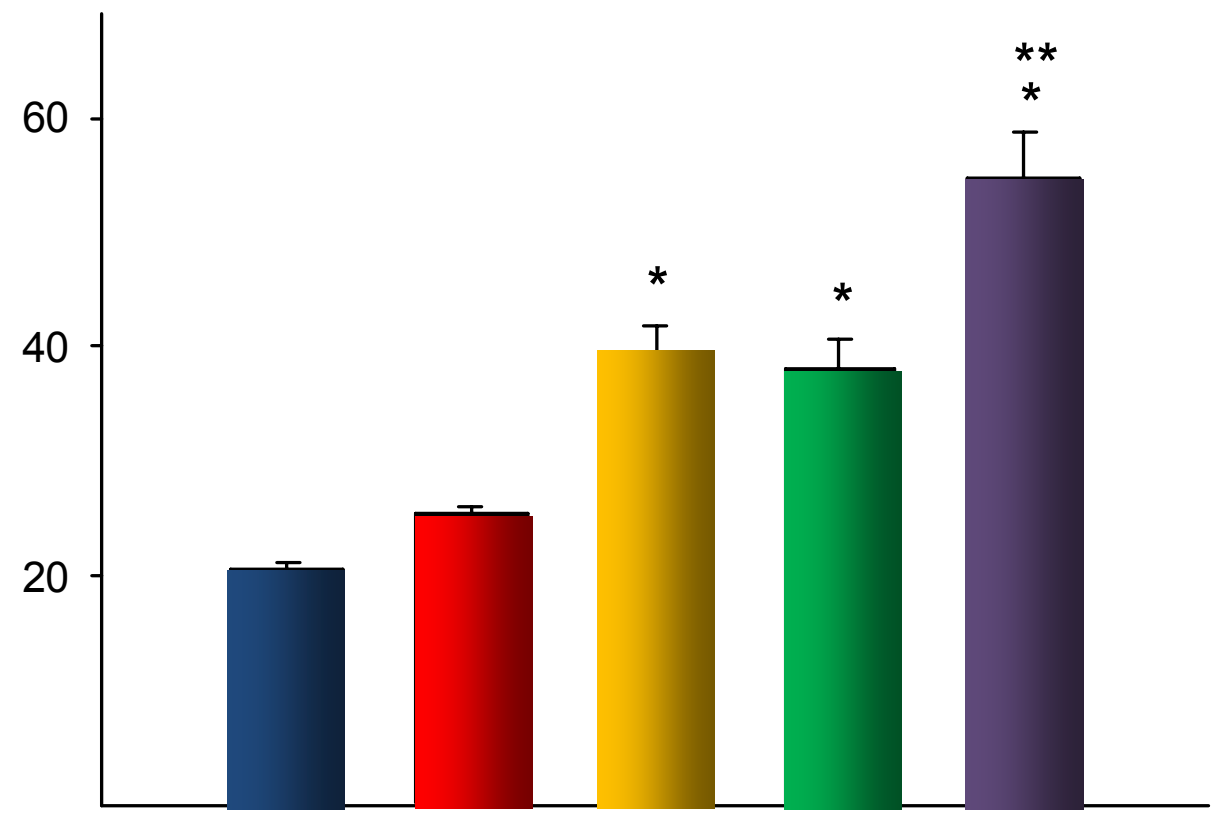

Figura 7. Valores do intercepto linear médio (Lm) nos cinco grupos (média e DP). Os grupos que receberam instilação de papaína mostraram valores mais elevados de $\mathrm{Lm}$ quando comparados com os grupos que receberam instilação de salina $(p<0,001)$. O grupo PHE apresentou valores maiores de Lm quando comparado aos grupos PS e PME $(p=0,001)$. 
A Figura 8 mostra fotomicrografias do parênquima pulmonar ao final do protocolo de exercício, 40 dias após a instilação de papaína (grupos SS e SHE) ou salina (grupos PS; PME e PHE) mais 10 semanas de atividade física. Nós podemos observar a integridade do parênquima alveolar nos grupos salina e a presença de destruição alveolar com alargamento e aumento dos espaços alveolares nos grupos que receberam instilação de papaína.

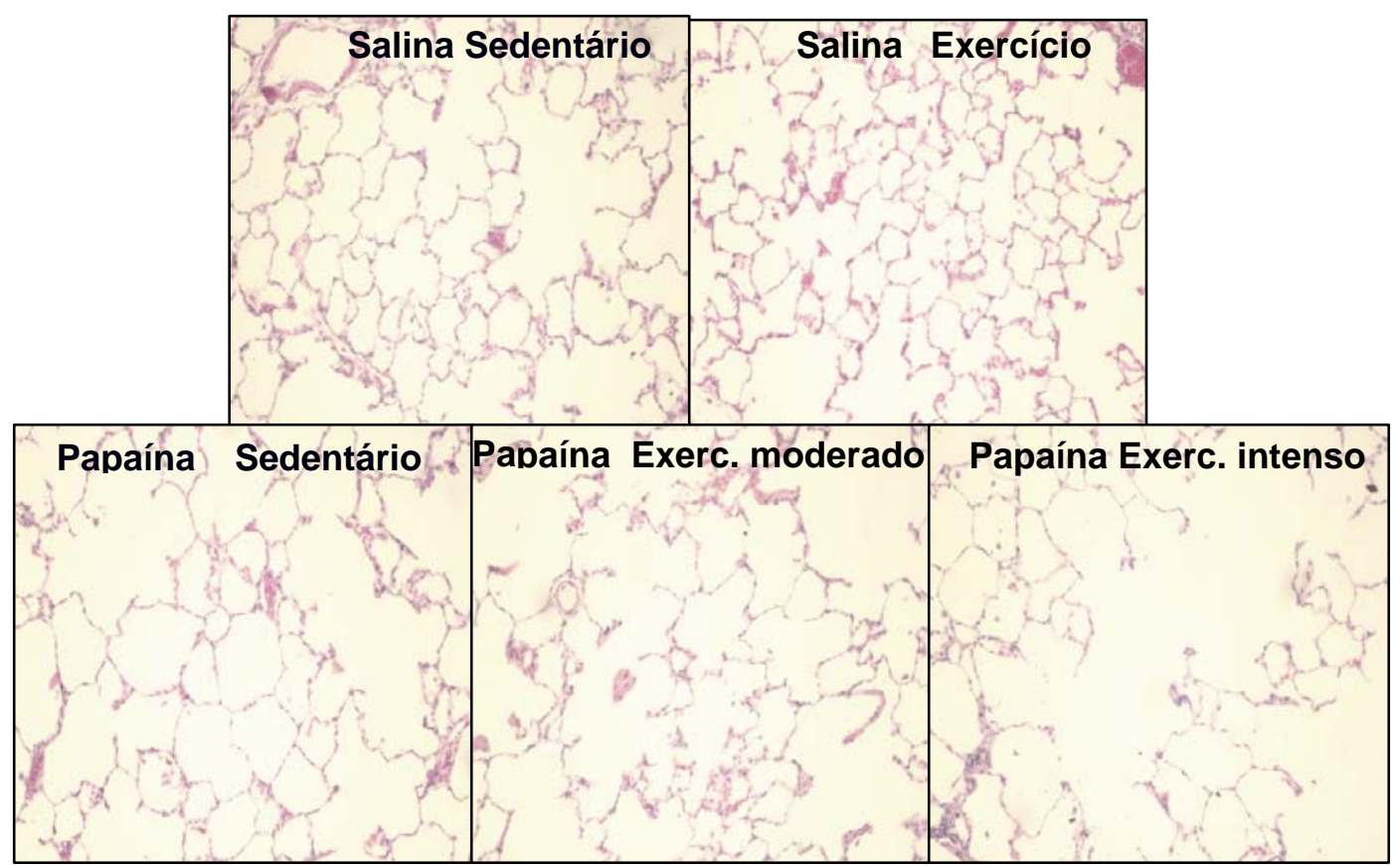

Figura 8. As fotomicrografias representam o parênquima pulmonar de ratos Wistar dos 5 grupos experimentais (aumento de 400x, coloração pela hematoxilina e eosina). 
4.4. PROPORÇÃO DE FIBRAS COLÁGENAS NO PARÊNQUIMA PULMONAR

A Figura 9 mostra a proporção de fibras colágenas no tecido alveolar. Os grupos que receberam solução de papaína (PHE, PME e PS) mostraram um discreto aumento na proporção do volume de fibras colágenas quando comparados com os animais que receberam solução salina (SS e SHE) ( $p=$ 0, 049). Não houve diferença significativa na proporção de volume de fibras colágenas entre os grupos que receberam instilação de papaína. 


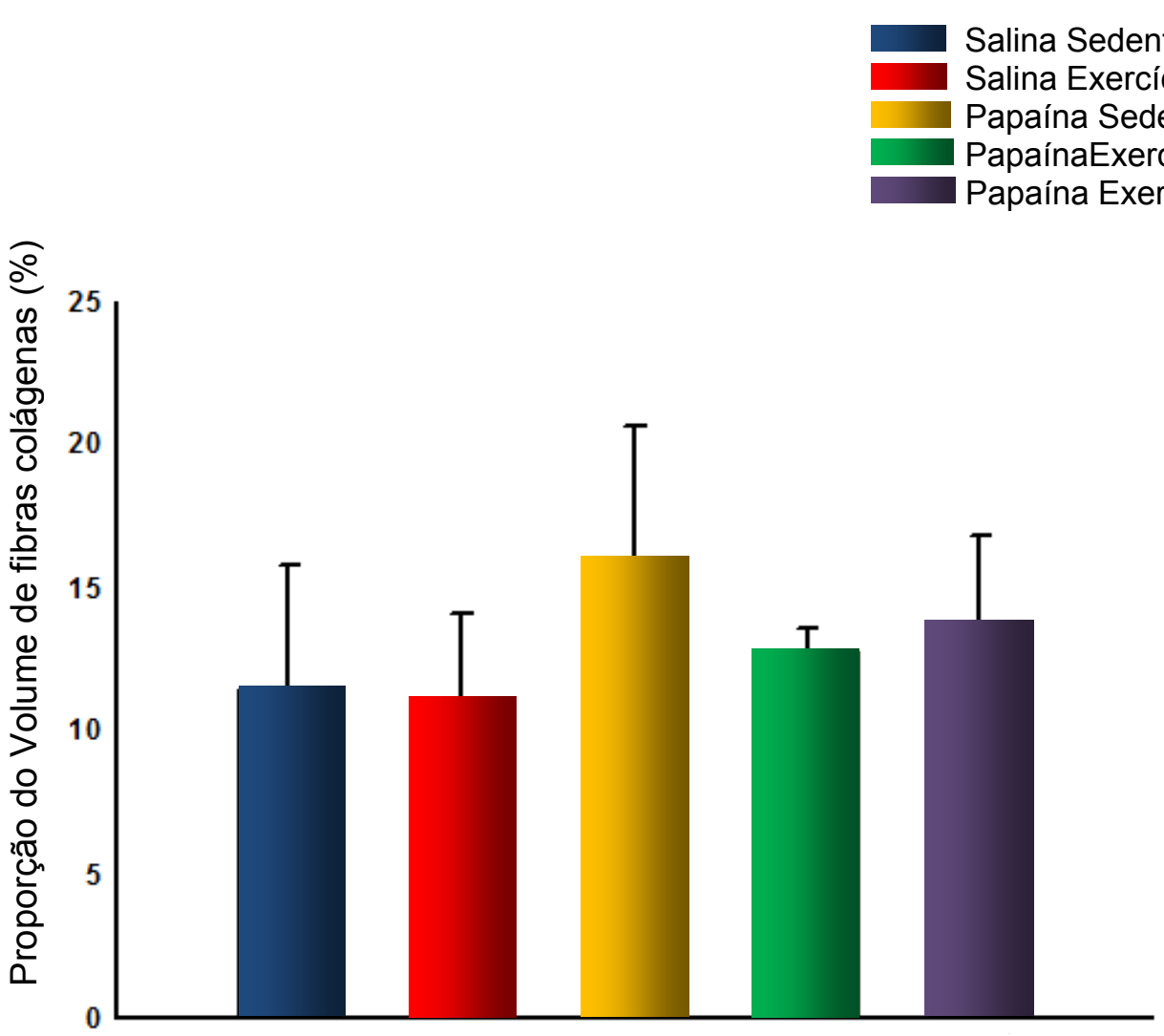

Figura 9. Proporção de fibras colágenas no parênquima alveolar nos cinco grupos experimentais. Os grupos PHE, PME e PS mostraram um discreto aumento nesta proporção em relação aos grupos SS e SHE ( $p=0,049)$. 


\subsection{ANÁLISE DA EXPRESSÃO DE ISOPROSTANO-8}

Os dados apresentados para isoprostano-8 correspondem ao quociente entre a área de parênquima positivo para o marcador estudado pela área total de parênquima.

A figura 10 mostra o índice de densidade ótica (IOD) da área do parênquima pulmonar positiva para o anticorpo anti-isoprostano-8, nos cinco grupos experimentais. Não houve diferença estatística significativa entre os grupos com $p=0,286$. 


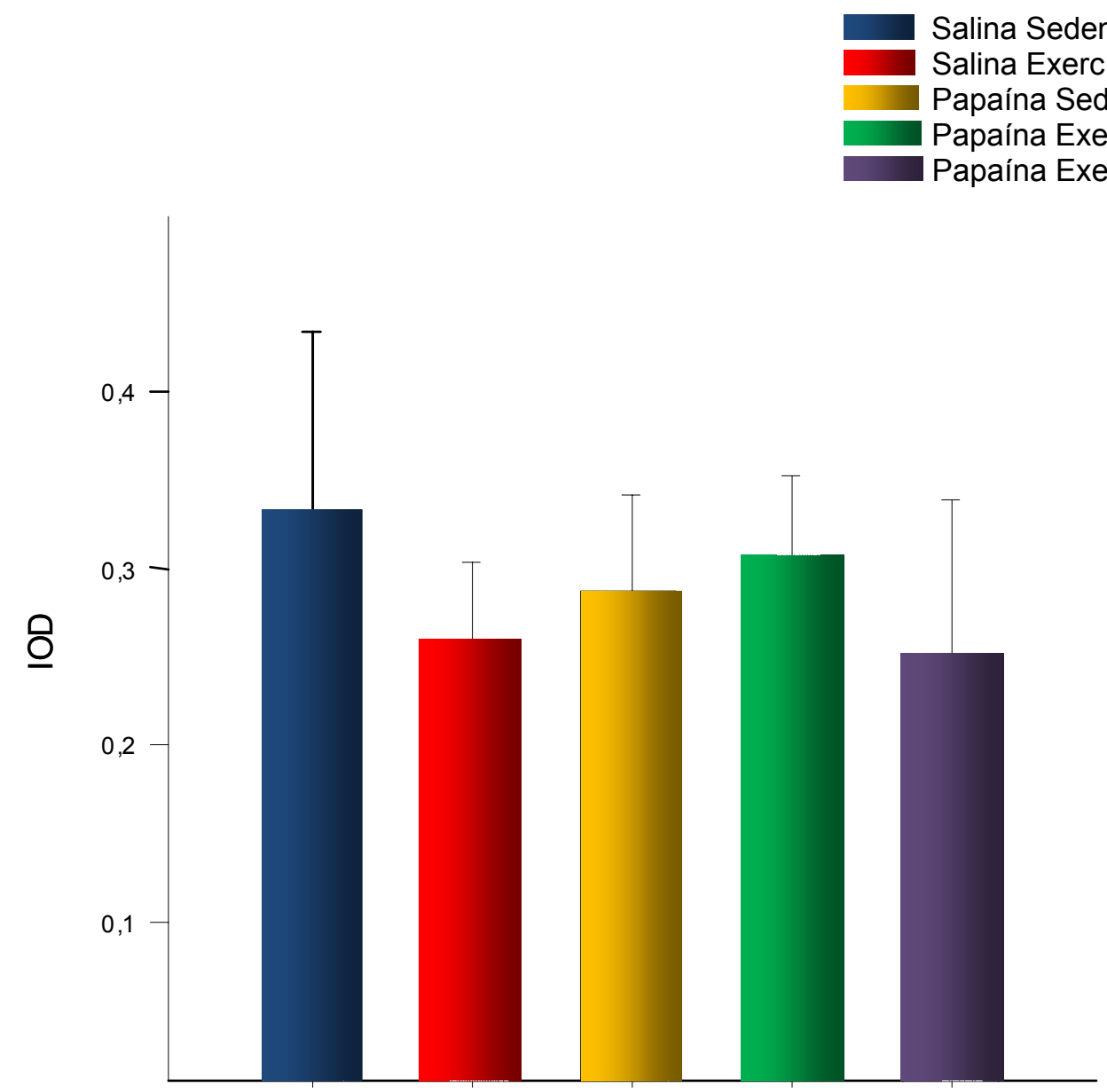

Figura 10. Intensidade de expressão do Isoprostano-8 no parênquima alveolar dos grupos experimentais. Não houve diferença estatística significativa entre os grupos $(p=0,286)$. 


\section{DISCUSSÃO}




\section{DISCUSSÃO}

Ratos Wistar tratados com papaína, para indução de enfisema pulmonar, e submetidos a diferentes intensidades de atividade física apresentaram diferentes graus de lesão pulmonar. Neste estudo verificamos que a atividade física de alta intensidade piorou o enfisema em ratos Wistar que receberam tratamento intratraqueal com papaína, enquanto os animais que receberam o mesmo tratamento, mas foram submetidos a um protocolo de exercício de intensidade moderada não apresentaram diferença quando comparados aos animais que não foram submetidos à atividade física e receberam papaína.

Em pacientes com DPOC a reabilitação pulmonar tem demonstrado ser efetiva na melhora da tolerância ao exercício e na melhora da qualidade de vida (Guell et al., 2000; Gold, 2009).

Entre os objetivos da reabilitação pulmonar destaca-se o aumento da tolerância ao exercício, aumento do metabolismo, redução do nível de dependência do paciente em relação aos cuidados médicos, melhora física e emocional nas atividades diárias com consequente melhora da qualidade de vida, diminuição da dispnéia, redução na ventilação, aumento no tempo de realização do teste de esforço entre outros (Corso, 2000; Clark et al., 2000; Bernard et al., 1999; Neder et al., 1997; Goldstein et al.,1994; Ribeiro et al., 
1994; Simpson et al., 1992). A intolerância ao exercício nos pacientes com DPOC parece ser não somente pela obstrução pulmonar, mas também pela combinação de alguns fatores extra-pulmonares. Existem vários estudos demonstrando a diminuição da endurance do sistema muscular esquelético em pacientes DPOC associado às alterações da função pulmonar. Atrofia e fraqueza dos músculos periféricos são comuns, levando a redução da capacidade física, entre outros fatores (Serres et al., 1998; Gold, 2009; Guell et al., 2000).

Uma meta-análise de Puhan, em 2005, demonstrou que pacientes com DPOC se beneficiam da reabilitação pulmonar após uma exacerbação, com melhora da capacidade física, da qualidade de vida e redução da mortalidade (Osthoff and Leuppi, 2010).

A destruição da arquitetura pulmonar pode também alterar a disposição normal das vias aéreas, contribuindo para o aumento da resistência destas (Barnes, Shapiro, Pauwels, 2003).

A escolha de um protocolo de reabilitação deve compreender uma avaliação individualizada e criteriosa para posterior adequação, segundo os valores obtidos na avaliação, das atividades a serem desenvolvidas pelo paciente. Tem-se realizado esforços para desenvolver um protocolo tolerável, porém efetivo aos pacientes DPOC, mas ainda não se chegou a 
um consenso sobre o tipo de atividade física mais eficiente para os pacientes DPOC e sobre o tipo de exercício.

Estudos experimentais em diferentes patologias, com intensidades diferentes de atividade física vêm sendo desenvolvidos, por exemplo, por Navarro et al. (2004), verificando o efeito do exercício moderado em ratos com relação ao comportamento desses animais e ao estresse oxidativo e Vrabas et al. (1999) verificando o efeito do treinamento físico intenso na redução da fadiga do diafragma. Mais recentemente, Fló et al., 2006 desenvolveram um protocolo de atividade física intensa, no enfisema pulmonar ainda em desenvolvimento, demonstrando efeitos deletérios no pulmão de ratos Wistar quando comparados aos ratos enfisematosos que não realizaram atividade física.

Objetivando a melhor compreensão da evolução da doença e também encontrar medidas terapêuticas, diversos modelos animais de DPOC foram desenvolvidos em diferentes espécies. A instilação pulmonar de enzimas elastolíticas como a elastase e a papaína tem sido largamente utilizada e seus resultados na morfologia pulmonar são similares ao enfisema humano, levando ao desenvolvimento de enfisema pulmonar em cerca de um mês (Hayes, 1975; Pushpakom, 1970, Shapiro, 2000). É sabido que roedores e seres humanos apresentam diferenças anatômicas e fisiológicas em suas árvores brônquicas, mas apresentam, com frequência, respostas semelhantes quando expostos a uma substância que induz lesão pulmonar 
(Dawkins et al., 2001). A escolha pelos ratos Wistar foi por apresentarem porte pequeno, serem facilmente mantidos no biotério e mais importante, desenvolverem enfisema pulmonar semelhante ao apresentado por seres humanos, quando submetidos à instilação intratraqueal de papaína (Fusco 2002). A escolha por utilizar papaína foi por induzir um enfisema pulmonar após uma única administração, além dos resultados na morfologia pulmonar estarem padronizados em nosso grupo de pesquisa e serem similares ao enfisema humano.

No estudo de Fló et al. os animais foram submetidos à atividade física intensa, com enfisema ainda em desenvolvimento e foi observada uma maior destruição do parênquima alveolar nos animais que realizaram atividade física intensa. Nosso estudo teve duas diferenças em relação ao estudo de Fló et al.: realizamos um protocolo de enfisema e exercício, avaliando duas diferentes intensidades de atividade física (leve-moderada e intensa) e estudamos ratos Wistar com enfisema já instalado.

Os animais do nosso estudo, em todos os grupos, independente do fato de terem recebido papaína ou não, apresentaram um aumento de peso significativo ao longo das 10 semanas, semelhante em todos os grupos. Este resultado foi semelhante ao trabalho de Fló com enfisema ainda em desenvolvimento, porém era esperado que os animais com enfisema já instalado tivessem uma diminuição do peso com relação ao grupo controle, pelo fato do enfisema resultar em um gasto energético maior. Em trabalhos 
anteriores, em que os animais foram instilados com papaína, observou-se diminuição do peso dos animais que receberam papaína somente nos primeiros dias. No entanto, ao longo das semanas seguintes, o peso dos animais instilados com salina ou com papaína sofreu aumentos similares (Boyde et al., 1980; Kobrle et al., 1982).

Assim como no trabalho de Fló e colaboradores, não foi observada diferença significativa dos valores de resistência (Rrs) do sistema respiratório em nosso experimento, quando comparamos os grupos no momento inicial e ao final do protocolo, assim como não foi observado diferença significativa entre os grupos, nos momentos inicial e final.

Com relação à elastância do sistema respiratório, houve um decréscimo significativo nos grupos que receberam instilação de solução de papaína, quando comparados aos grupos que receberam instilação de solução salina. Houve ainda diferença significativa entre os valores iniciais e os valores finais de elastância em todos os grupos, com exceção do grupo salina exercício intenso. A diminuição da elastância do sistema respiratório observada no grupo que recebeu solução salina pode simplesmente ser um efeito da idade dos animais. No entanto não foi observada diferença significativa entre os grupos que realizaram diferentes intensidades de atividade física. Podemos observar por estes resultados que os grupos papaína desenvolveram enfisema devido à diminuição das fibras elásticas em comparação aos grupos salina. Porém, as diferentes intensidades de 
atividade física não foram capazes de produzir um enfisema mais intenso em um dos grupos. O alargamento dos espaços aéreos tem sido associado com a diminuição das propriedades elásticas do pulmão, a análise morfométrica ainda é considerada a medida mais confiável para detectar enfisema pulmonar (Foronjy et al., 2006; Guerassimov et al., 2004).

A quantificação do enfisema pulmonar foi realizada por meio da medida do intercepto linear médio ( $\mathrm{Lm})$. A medida de $\mathrm{Lm}$ é um índice do diâmetro médio dos espaços aéreos e é um marcador da distensão alveolar, podendo ser calculado por técnicas morfométricas e de análise de imagem.

Neste estudo as medidas de Lm foram feitas por meio de técnicas convencionais de contagem de interceptos. As lâminas foram observadas em microscópio óptico comum em aumento de 200x, sobre a objetiva foi colocado um retículo e as medidas foram realizadas em todos os lobos pulmonares do pulmão esquerdo e direito.

Os dados encontrados neste trabalho são compatíveis com o desenvolvimento do enfisema em ratos publicados em outros estudos e são similares ao enfisema humano (Hayes, 1975; Pushpakom, 1970). O tempo de 40 semanas utilizado neste estudo foi suficiente para produzir uma lesão detectável pelas medidas tradicionais de Lm (Shapiro, 2000). Foi possível observar alargamento dos espaços aéreos em todos os lobos pulmonares dos animais que receberam instilação de papaína sendo que o grupo que 
realizou atividade física intensa apresentou um desenvolvimento maior de áreas enfisematosas quando comparado ao grupo que realizou atividade leve-moderada, como mostra a Figura 7.

Existem vários estudos anteriores que correlacionam atividade física e enfisema pulmonar, mas até o presente momento, que seja de nosso conhecimento, não existem estudos que correlacionam os efeitos da atividade física leve-moderada e intensa com as alterações provocadas no pulmão de um modelo animal de enfisema.

O protocolo de atividade intensa utilizado foi baseado em um protocolo anterior de atividade física usado em ratos, em nosso laboratório, por Fló et al. e em outros protocolos já estabelecidos na literatura para atividade intensa (Vrabas et al. 1999) e Zonderland et al. 1999). O protocolo de atividade leve-moderada foi baseado nos estudos de Navarro et al (2003) e Hashimoto et al (2004) e seus efeitos já se apresentam previamente descritos e estabelecidos na literatura (Murphy et al. 2004).

Nos animais submetidos às duas intensidades diferentes de atividade física, exercício leve-moderado e exercício intenso, após dez semanas de treinamento, foi observada uma maior destruição da parede alveolar, com aumento significativo nos valores de $\mathrm{Lm}$ nos grupos que receberam instilação de papaína quando comparados com os grupos que receberam instilação de salina. Porém, entre os grupos papaína, o grupo que realizou 
atividade física intensa (PHE) mostrou um aumento maior nos valores de $\mathrm{Lm}$ quando comparado com o grupo que realizou atividade leve-moderada (PME). Não foi observada diferença significativa entre os grupos PS e PME assim como entre os grupos que não foram submetidos à atividade física. Esses resultados sugerem que a atividade física intensa aumentou a destruição do parênquima pulmonar neste modelo animal de enfisema com relação ao exercício de moderada intensidade, que apresentou uma maior integridade da parede alveolar.

Geralmente, concomitante à destruição e alargamento do parênquima alveolar observados no enfisema pulmonar, ocorre uma reorganização das fibras do tecido conectivo durante o desenvolvimento do enfisema pulmonar (Chung e Adcock, 2008; Li et al., 2002). No nosso estudo, foi observado um aumento na proporção do volume de fibras colágenas do parênquima pulmonar de todos os grupos de animais que receberam instilação de papaína independente da intensidade de atividade física. Embora em nosso estudo a atividade física intensa tenha piorado a destruição alveolar, não apresentou efeito no remodelamento pulmonar. Não há um consenso na literatura correlacionando a destruição alveolar com o remodelamento da matriz extracelular. Porem é importante considerar que foi avaliado o total de fibras colágenas nos septos alveolares, sem considerar os diferentes tipos de colágeno. 
Para tentar explicar a maior destruição alveolar (Lm) observada no grupo que realizou atividade intensa, foi levantada a hipótese de que o estresse oxidativo fosse o causador de tal evento. $\mathrm{O}$ estresse oxidativo, um desequilíbrio entre oxidantes e antioxidantes, está aumentado em pacientes com DPOC, principalmente em exacerbações (Biermacki et al., 2003). A presença do estresse oxidativo tem conseqüências importantes em diversos eventos da patogênese da DPOC, como a lesão do epitélio dos espaços alveolares, a hipersecreção de muco, o remodelamento da matriz extracelular (MEC) entre outros (Rahman, 2005). Considerando que o exercício aeróbico intenso pode interferir no balanço oxidante/antioxidante resultando no aumento da produção de oxidantes, esse desequilíbrio levaria a piora da destruição alveolar, ou seja, a um aumento da destruição alveolar observada nos animais que realizaram atividade física intensa, podendo então induzir o estresse oxidativo.

Para estudarmos o estresse oxidativo em nosso protocolo experimental medimos a expressão do isoprostano-8 nos tecido pulmonar dos ratos dos cinco grupos. Os isoprostanos são compostos resultantes da peroxidação do ácido aracdônico das membranas celulares, sendo bastante utilizados como marcadores de estresse oxidativo em doenças pulmonares. Estes compostos encontram-se aumentados em indivíduos que possuem doenças pulmonares obstrutivas crônicas (Pratico et al.,1998), sendo considerados bons marcadores de estresse oxidativo tanto em seres humanos como em animais. 
Em nosso estudo, não observamos diferença entre os cinco grupos quando medimos o isoprostano-8. Portanto o estresse oxidativo não seria o causador da maior destruição alveolar no grupo que realizou atividade física intensa.

Outra possível explicação para essa maior destruição alveolar seria o efeito da hiperventilação (aumento do volume corrente e freqüência respiratória) que acompanha o exercício intenso, causando uma maior distensão dos septos alveolares e levando a uma maior quantidade de rupturas. Há poucos estudos que tentam elucidar esta questão. No estudo de Gelb e colaboradores (1999) foi observado que pacientes em fase terminal de enfisema submetidos à cirurgia de redução de volume pulmonar perdem os benefícios na função pulmonar no decorrer do tempo, podendo tornar-se ainda mais limitados no período pós-operatório. A possível explicação para este fato seria o aumento das forças mecânicas exercidas sobre o tecido conjuntivo em virtude da hiperinsuflação sofrida pelo pulmão remanescente. West em 1971 sugere que o estresse mecânico no pulmão é mais intenso nas áreas mais afetadas pelo enfisema. Em estudo mais recente de Kononov e colaboradores (2001) foi desenvolvida uma técnica para medir as propriedades mecânicas de fatias do tecido pulmonar e visualizar a deformação das fibras de colágeno e elastina em ratos que receberam instilação intratraqueal de elastase. Foi observado um remodelamento tecidual significativo com espessamento das fibras eláticas e 
colágenas. Mais importante é que durante o estiramento, as fibras de elastina e colágeno recém depositadas apresentaram maior distorção quando comparadas as fibras presentes em tecido pulmonar normal. E mais, estes autores observaram que o limiar de falência mecânica do colágeno, do tecido enfisematoso, está reduzido durante 0 estiramento quando comparado ao tecido pulmonar normal. É bem estabelecido, que a ventilação mecânica com volumes pulmonares elevados, resulta em maior injúria do tecido pulmonar, em especial em pacientes com lesão pulmonar aguda como, por exemplo, a síndrome do desconforto respiratório agudo (Amato et al., 1993; Amato et al., 1995; Amato et al., 1998).

Shapiro sugeriu a existência de um processo inflamatório dinâmico que perdura mesmo depois do enfisema instalado; sugerindo que ocorram inflamações múltiplas (em células provavelmente estruturais) interagindo para piorar a destruição alveolar na DPOC, e que o foco em células individuais e proteinases isoladamente não proporcionam uma compreensão global do processo da doença.

Outras alterações fisiológicas e metabólicas induzidas pela atividade física também poderiam ter contribuído para o aumento da lesão alveolar induzida por papaína, como alterações hormonais e hemodinâmicas. 
Esses resultados podem ter repercussão clínica importante nos programas de reabilitação respiratória, uma vez que podem orientar, pelo menos em parte, os programas de atividade física em pacientes enfisematosos com relação ao grau de intensidade utilizado, com a finalidade de proporcionar um maior benefício ao paciente, melhorando a capacidade respiratória sem aumentar o grau de destruição pulmonar causado pela atividade intensa, como apresentado em nosso resultado.

Há, entretanto, a necessidade de outros estudos para elucidar os mecanismos precisos envolvidos na maior destruição da parede alveolar, induzidos pela atividade física intensa. 
CONCLUSÕES 


\section{CONCLUSÕES}

A atividade física intensa piorou o enfisema pulmonar induzido pela administração de solução de papaína em ratos Wistar.

Essa piora do enfisema não foi observada em ratos submetidos a um protocolo de atividade física leve/moderada. 
REFERÊNCIAS 


\section{Referências}

1. Rabe KF, Hurd S, Anzueto A, Barnes PJ, Buist SA, Calverley P, Fukuchi Y, Jenkins C, Rodriguez-Roisin R, van Weel C and Zielinski J; Global Initiative for Chronic Obstrutive Lung Disease. Global Strategy for the Diagnosis, Management, and Prevention of Chronic Obstructive Pulmonary Disease: GOLD Executive Summary. Am J Respir Crit Care Med Update, 2009; 176: 532-555.

2. Rabe KF, Hurd S, Anzueto A, Barnes PJ, Buist SA, Calverley P, Fukuchi Y, Jenkins C, Rodriguez-Roisin R, van Weel C and Zielinski J; Global Initiative for Chronic Obstrutive Lung Disease. Global Strategy for the Diagnosis, Management, and Prevention of Chronic Obstructive Pulmonary Disease: GOLD Executive Summary. Am J Respir Crit Care Med Update, 2008; 176: 532-555.

3. Rabe KF, Hurd S, Anzueto A, Barnes PJ, Buist SA, Calverley P, Fukuchi Y, Jenkins C, Rodriguez-Roisin R, van Weel C and Zielinski J; Global Initiative for Chronic Obstrutive Lung Disease. Global Strategy for the Diagnosis, Management, and Prevention of Chronic Obstructive Pulmonary Disease: GOLD Executive Summary. Am J Respir Crit Care Med 2007; 176 : 532-555.

4. Halbert RJ, Natoli JL, Gano A, Badamgarav E, Buist AS, Mannino DM. Global burden of COPD: systematic review and meta-analysis. Eur Respir J. 2006 Sep;28(3):523-32.

5. Van den Boom G, van Schayck CP, van Möllen MP, Tirimanna PR, den Otter JJ, van Grunsven PM, Buitendijk MJ, van Herwaarden CL, van Weel C. Active detection of chronic obstructive pulmonary disease and asthma in the 
general population. Results and economic consequences of the DIMCA program. Am J Respir Crit Care Med 1998; 158: 1730-1738.

6. Menezes AM, Perez-Padilla R, Jardim JR, Muino A, Lopez MV, Valdivia G, et al. Chronic obstructive pulmonary disease in five Latin American cities (the PLATINO study): a prevalence study. Lancet. 2005 Nov 26;366(9500):187581.

7. Menezes AM, Perez-Padilla R, Jardim JR, Muino A, Lopez MV, Valdivia G, et al. Chronic obstructive pulmonary disease in five Latin American cities (the PLATINO study): a prevalence study. Lancet. 2005 Nov 26;366(9500):187581.

8. Lopez AD, Shibuya K, Rao C, Mathers CD, Hansell AL, Held LS, Schmid V, Buist S. Chronic obstructive pulmonary disease: current burden and future projections. Eur Respir J 2006; 27:397-412.

9. Jardim J, Oliveira J, Nascimento O. II Consenso Brasileiro de doença pulmonar obstrutiva crônica (DPOC). J Pneumol, 2004; 30: S1-S42.

10. Behrendt CE. Mild and Moderate-to-Severe COPD in Nonsmokers: Distinct Demographic Profiles. Chest 2005;128:1239-1244.

11. Jardim J, Oliveira J, Nascimento O. II Consenso Brasileiro de doença pulmonar obstrutiva crônica (DPOC). Revisão de alguns aspectos de epidemiologia e tratamento da doença estável. J Pneumol, 2006; 30:1-23.

12. Balmes J, Becklake M, Blanc $P$, Henneberger $P$, Kreiss K, Mapp C, Milton D, Schwartz D, Toren K, Viegi G.American Thoracic Society Statement: Occupational contribution to the burden of airway disease. $A m \mathrm{~J}$ Respir Crit Care Med. 2003 Mar 1;167:787-97. 
13. Salvi SS, Barnes PJ. Chronic obstructive pulmonary disease in nonsmokers. Lancet 2009; 374: 733-743.

14. Odonnell DE; Webb KA. Breathlessness in patients with severe chronic airflow limitation. Physiologic correlations. Chest 1992; 102: 824-831.

15. Eltayara L, Becklake MR, Volta CA, Milic-Emili J. Relationship between chronic dyspnea and expiratory flow limitation in patients with chronic obstructive pulmonary disease. Am J Respir Crit Care Med. 1996;154:17261734.

16. Ambrosino N, Scano G. Measurement and treatment of dyspnoea Respiratory Medicine 2001; 95: 539-547.

17. Calverley PM $A$ and Koulouris NG. Flow limitation and dynamic hyperinflation: key concepts in modern respiratory physiology Eur Respir $\mathrm{J}$ 2005; 25:186-199.

18. O'Donnell DE, Lam M, Webb KA. Spirometric Correlates of Improvement in Exercise Performance after Anticholinergic Therapy in Chronic Obstructive Pulmonary Disease. Am. J. Respir. Crit. Care Med. 1999; 160: 542-549.

19. Hadcroft J, Calverley PMA. Alternative methods for assessing bronchodilator reversibility in chronic obstructive pulmonary disease. Thorax 2001; 56: 713-720.

20. O'Donnell DE, D'arsigny $C$, and Webb KA. Effects of Hyperoxia on Ventilatory Limitation during Exercise in Advanced Chronic Obstructive Pulmonary Disease. Am. J. Respir. Crit. Care Med. 2001; 163: 892-898. 
21. Koulouris NG, Dimopoulou I, Valta P, Finkelstein R, Cosio MG, and MilicEmili J. Detection of expiratory flow limitation during exercise in COPD patients Journal of Applied Physiology 1997; 82: 723-731.

22. Lecture RSM, Milic-Emili J. Expiratory flow limitation. Detection and clinical implications. Chest 2000; 117: 219-223.

23. Ayers ML, Mejia R, Ward J, Lentine T and Mahler DA. Effectiveness of salmeterol versus ipratropium bromide on exertional dyspnoea in COPD. Eur Respir J 2001; 17:1132-1137

24. Aliverti A, Stevenson N, Dellacà RL, Mauro AL, Pedotti A, Calverley PMA. Regional chest wall volumes during exercise in chronic obstructive pulmonary disease. Thorax 2004;59:210-216.

25. Hogg J. Pathophysiology of airflow limitation in chronic obstructive pulmonary disease. Lancet 2004; 364: 709-721.

26. Barnes PJ, Shapiro SD, Pauwels RA. Chronic obstructive pulmonary disease: molecular and cellular mechanisms. Eur Respir J. 2003 Oct;22(4):672-88.

27. Biernacki WA, Kharitonov SA, Barnes PJ. Increased leukotriene B4 and 8-isoprostane in exhaled breath condensate of patients with exacerbations of COPD. Thorax. 2003 Apr;58(4):294-8.

28. Rahman I. Oxidative Stress. In: Barnes PJ. Cronic Obstrutive Pulmonary Disease: Cellular and Molecular mechanismis. $1^{\text {st }}$ ed. Boca Raton: Taylor and Francis; 2005. p.279-325. 
29. Jeffery PK. Remodeling and inflammation of bronchi in asthma and chronic obstructive pulmonary disease. Proc Am Thorac Soc 2004; 1:176183.

30. Sturton G, Persson C, Barnes PJ. Small airways: an important but neglected target in the treatment of obstructive airway diseases. Trends in Pharmacological Sciences 2008; 29: 340-345.

31. Wang RD, Tai H, Xie C, Wang X, Wright JL, Churg A. Cigarette Smoke Produces Airway Wall Remodeling in Rat Tracheal Explants. Am J Respir Crit Care Med 2003; 168: 1232-1236.

32. Wang RD, Wright JL, Churg A. Transforming growth factor-beta1 drives airway remodeling in cigarette smoke-exposed tracheal explants. $A m \mathrm{~J}$ Respir Cell Mol Biol. 2005; 33:387-93.

33. $\mathrm{N}$ J Kenyon, R W Ward, G McGrew, J A Last TGF- $\beta_{1}$ causes airway fibrosis and increased collagen I and III mRNA in mice. Thorax 2003;58:772777.

34. de Boer WY, van Schadewijk A, Sont JK, Sharma HS, Stolk J, Hiemstra PS, van Krieken JH. Transforming growth factor b1 and recruitment of macrophages and mast cells in airways in COPD. Am J Respir Crit Care Med 1998; 158: 1951-1957.

35. Takizawa H, Tanaka M, Takami K, Ohtoshi T, Ito K, Satoh M, et al. Increased expression of transforming growth factor-beta1 in small airway epithelium from tobacco smokers and patients with chronic obstructive pulmonary disease (COPD). Am J Respir Crit Care Med 2001 May;163(6):1476-83. 
36. Shapiro SD, Ingenito EP. The pathogenesis of chronic obstructive pulmonary disease: advances in the past 100 years. Am J Respir Cell Mol Biol 2005 May;32 (5):367-72.

37. Finlay GA, O'Donnell MD, O'Connor CM, Hayes JP, FitzGerald MX. Elastin and collagen remodeling in emphysema. A Scanning Electron Microscopy Study. Am J Pathol 1996, 149:1405-1415.

38. Cardoso W, Sekhon H, Hyde DM, Thurlbeck WM Collagen and elastin in human pulmonary emphysema. Am Rev Respir Dis 1993; 147:975-981.

39. Vlahovic G, Russell ML, Mercer RR, Crapo JD. Cellular and Connective Tissue Changes in Alveolar Septal Walls in Emphysema. Am. J. Respir. Crit. Care Med, Volume 160, Number 6, December 1999, 2086-2092.

40. Black PN, Ching PST, Beaumont B, Ranasinghe S, Taylor G, Merrilees MJ. Changes in elastic fibres in the small airways and alveoli in COPD. Eur Respir J 2008; 31:9981004.

41. Güell R, Casan P , Belda J, Sangenis M, Morante F, Sanchis J. Longterm Effects of Outpatient Rehabilitation of COPD. A Randomized Trial. Chest 2000;117: 976-983.

42. S. Dal Corso, SR Duarte, JA Neder, C. Malaguti, MB de Fuccio, CA de Castro Pereira.Determinantsof performance in the 6MST. J Sports Med 2000; 21: 263-269.

43. Goldstein RS, Gort EH, Avendano MA, Stubbing D, Guyatt GH Randomised controlled trial of respiratory rehabilitation. The Lancet 1994, 344:1394 - 1397. 
44. Ribeiro AS, Jardim JRB, Nery LE. Avaliação da tolerância ao exercício em pacientes com doença pulmonar obstrutiva crônica. Teste de caminhada por seis minutos versus cicloergometria. Jornal de Pneumologia 1994; 20:112-116.

45. Neder JA, Andreoni S, Castelo-Filho A, Nery LE. Reference values for lung function tests. I. Statics volumes. Braz J Med Biol Res 1999; 32:703717.

46. Serres I, PhD; Ve'ronique Gautier, MD; Alain Varray, PhD; and Christian Pre'faut, MD Impaired Skeletal Muscle Endurance Related to Physical Inactivity and Altered Lung Function in COPD Patients*. Chest 1998; 113:900-05.

47. Peigang Y, Marini JJ. Ventilation of patients with asthma and chronic obstructive pulmonary disease. Curr Opin Crit Care 2002;8(1):70-6.

48. Riera HS, MD, Teodoro Montemayor Rubio, MD, Francisco Ortega Ruiz, MD, Pilar Cejudo Ramos, MD, Daniel Del Castillo Otero, MD, Teresa Elias Hernandez, MD, and Jose Castillo Gomez, MD. Inspiratory Muscle Training in Patients With COPD- Effect on Dyspnea, Exercise Performance, and Quality of Life. Chest September 2001 vol. 120 no. 3 748-756

49. Orozco-Levi M. Structure and function of the respiratory muscles in patients with COPD: impairment or adaptation. Eur Respir J 22(46): 41s-51s, 2003.

50. Simpson K, Killian K, McCartney N, et al. Randomized controlled trial of weightlifting exercise in patients with chronic airflow obstruction. Thorax 1992; 47:70-75. 
51. Clark CJ, Cochrane LM, Mackay E, et al. Skeletal muscle strength and endurance in patients with mild COPD and the effects of weight training. Eur Respir J 2000; 15:92-97.

52. Bernard S, Whittom F, LeBlanc $P$, et al. Aerobic and strength training in patients with chronic obstructive pulmonary disease. Am J Respir Crit Care Med 1999; 159:896-901.

53. Lacasse $Y$, Brosseau L, Milne S, et al. Pulmonary rehabilitation for COPD. Cochrane Database Syst Rev 2002; 3:CD003793

54. Casaburi R. Exercise training in chronic obstructive lung disease. In: Casaburi R, Petty TL, eds. Principles and practice of pulmonary rehabilitation. Philadelphia, PA: W.B. Saunders, 1993; 204-224

55. Mador MJ, MD; Bozkanat E, MD; Aggarwal A, MD; Shaffer M, NP; and Kufel TJ, MD, FCCP. Endurance and Strength Training in Patients With COPD*. Chest 2004; 125; 2036-2045.

56. Puhan AM, Scharplatz M, Troosters $T$ and Steurer J. Respiratory rehabilitation after acute exacerbation of COPD may reduce risk for readmission and mortality - a systematic review Respiratory Research 2005, $6: 54$

57. Osthoff M, Leuppi JD, Management of Chronic Obstructive Pulmonary Disease Patients after Hospitalization for Acute Exacerbation Department of Internal Medicine, University Hospital Basel, Basel, Switzerland Respiration 2010;79:255-261. 
58. Puhan MA, Schunemann HJ, Buesching G, vanOort E, Spaar A and Frey M. COPD patients' hability to follow exercise influences short-term outcomes of rehabilitation. Eur Respir J 2008; 31: 304-310.

59. Hayes JA, Korthy A, Snider GL. The pathology of elastase-induced panacinar emphysema in hamsters. J Pathol 1975;117:1-14.

60. Pushpakom, R., JC Hogg, AJ Woolcock, AE Angus, PT Macklem and WM Thurlbeck. Experimental papaininduced emphysema in dogs. Am Rev Respir Dis 1970; 102: 778-789.

61. Shapiro SD. Animal models for COPD. Chest 2000 May; 117(5 Suppl 1):223S-7S.

62. Fló C, Lopes FD, Kasahara DI, Silva AC, Jesus RC, Rivero DH, Saldiva $\mathrm{PH}$, Martins MA, Jacob-Filho W. Effects of exercise training on papaininduced pulmonary emphysema in Wistar rats. J Appl Physiol 2006; 100(1):281-385.

63. Sahebjami H, Vassallo CL. Exercise stress and enzyme-induced emphysema. J Appl Physiol 1976;41(3):332-335.

64. Martorana PA, van Even P,. Schaper J. The effect of lung growth on the evolution of elastase-induced emphysema in the hamster. Lung 1982; 160:19-27.

65. Cooper CB. The Connection Between Chronic Obstructive Pulmonary Disease Symptoms and Hyperinflation and Its Impact on Exercise and Function. The American Journal of Medicine 2006; 119 (10A): S21-S31.

66. McArdle W, Katch FI, Katch VL. Fisiologia do Exercício, Energia, Nutrição e Desempenho Humano. 4a ed. Rio de Janeiro: Ed. Guanabara Koogan; 1998. 
67. Denadai BS. Índices Fisiológicos de Avaliação Aeróbia: Conceitos e Aplicações. Ribeirão Preto: UNESP; 1999.

68. Pedersen BK, Hoffman-Goetz L. Exercise and the immune system: regulation, integration, and adaptation. Physiol Rev. 2000 Jul; 80(3):1055-81.

69. Alessio HM, Goldfarb AH. Lipid peroxidation and scavenger enzymes during exercise: adaptive response to training. J Appl Physiol 1988 Apr; 64(4):1333-6.

70. Radak Z, Naito H, Kaneko T, Tahara S, Nakamoto H, Takahashi R, et al. Exercise training decreases DNA damage and increases DNA repair and resistance against oxidative stress of proteins in aged rat skeletal muscle. Pflugers Arch 2002 Nov; 445(2):273-8.

71. Radak Z, Chung HY, Goto S. Systemic adaptation to oxidative challenge induced by regular exercise. Free Radic Biol Med 2008 Jan 15; 44(2):153-9.

72. Li H, Wallerath T, Munzel T, Forstermann U. Regulation of endothelialtype NO synthase expression in pathophysiology and in response to drugs. Nitric Oxide 2002 Nov;7(3):149-64.

73. Radak Z, Chung HY, Goto S. Exercise and hormesis: oxidative stressrelated adaptation for successful aging. Biogerontology 2005; 6(1):71-5.

74. Petersen AM, Pedersen BK. The anti-inflammatory effect of exercise. $J$ Appl Physiol 2005 Apr; 98(4):1154-62.

75. Moldoveanu Al, Shephard RJ, Shek PN. The cytokine response to physical activity and training. Sports Med 2001 Feb; 31(2):115-44.

76. Zieker D, Zieker J, Dietzsch J, Burnet M, Northoff H, Fehrenbach E. CDNA-microarray analysis as a research tool for expression profiling in 
human peripheral blood following exercise. Exerc Immunol Rev 2005;11:8696.

77. Costa Rosa L, Vaisberg, MW. Influências do exercício na resposta imune. Rev Bras Med Esporte 2002; 8:167-72.

78. Cannon JG, Meydani SN, Fielding RA, Fiatarone MA, Meydani M, Farhangmehr $\mathrm{M}$, et al. Acute phase response in exercise. II. Associations between vitamin E, cytokines, and muscle proteolysis. Am J Physiol 1991 Jun; 260(6 Pt 2):R1235-40.

79. Lakier Smith L. Overtraining, excessive exercise, and altered immunity: is this a T helper-1 versus T helper-2 lymphocyte response? Sports Med 2003; 33(5):347-64.

80. Lacasse Y, Wong E, Guyatt GH, King D, Cook DJ, Goldstein RS. Metaanalysis of respiratory rehabilitation in chronic obstructive pulmonary disease. Lancet 1996 Oct 26; 348(9035):1115-9.

81. Principles of Laboratory Animal Care" published by the National Institutes of Health (NIH publication 86-23, revised 1985).

82. Navarro A, Gomez C, López-Cepero JM, Boveris A. Beneficial effects of moderate exercise on mice aging: survival, behavior, oxidative stress, and mitochondrial electron transfer. Am J Physiol Regul Integr Comp Physiol 2004; 286(3):R505-511.

83. Hashimoto T, Kambara N, Nohara R, Yazawa M, Taguchi S. Expression of MHC-beta and MCT1 in cardiac muscle after exercise training in myocardial-infarcted rats. J Appl Physiol 2004; 97(3): 843-851. 
84. Vrabas IS, Dodd SL, Powers SK, Hughes M, Coombes J, Fletcher L, Demirel $H$, Reid MB. Endurance training reduces the rate of diaphragm fatigue in vitro. Med Sci Sports Exerc 1999; 31(11):1605-1612.

85. Zonderland ML, Bär PR, Reijneveld JC, Spruijt BM, Keizer HA, Glatz JF. Different metabolic adaptation of heart and skeletal muscles to moderateintensity treadmill training in the rat. Eur J Appl Physiol Occup Physiol 1999; 79(5):391-396.

86. Wagers S, Lundblad L, Moriya HT, Bates JH, Irvin CG. Nonlinearity of respiratory mechanics during bronchoconstriction in mice with airway inflammation J Appl Physiol 2002; 92: 1802-1807.

87. Mauad T, Xavier AC, Saldiva PH, Dolhnikoff M. Elastosis and fragmentation of fibers of the elastic system in fatal asthma. Am J Respir Crit Care Med 1999;160(3): 968-975.

88. Margraf LR, Tomashefski JF Jr, Bruce MC, Dahms BB. Morphometric analysis of the lung in bronchopulmonary dysplasia. Am Rev Respir Dis $1991 ; 143(2): 391-400$.

89. Prado CM, Leick-Maldonado EA, Yano L, Leme AS, Capelozzi VL, Martins MA, Tibério IF. Effects of nitric oxide synthases in chronic allergic airway inflammation and remodeling. Am J Respir Cell Mol Biol 2006; 35(4): 457-465.

91. Murphy EA, Davis JM, Brown AS, Carmichael MD, Van Rooijen N, Ghaffar A, Mayer EP. Role of lung macrophages on susceptibility to respiratory infection following short-term moderate exercise training. Am J Physiol Regul Integr Comp Physiol 2004; 287(6): R1354-1358. 
92. Murphy EA, Davis JM, Brown AS, Carmichael MD, Mayer EP, Ghaffar A. Effects of moderate exercise and oat beta-glucan on lung tumor metastases and macrophage antitumor cytotoxicity. J Appl Physiol 2004; 97(3): 955-59.

93. De Angelis K, Wichi RB, Jesus WRA, Moreira ED, Krieger EM, Irigoyen MC. Exercise training changes autonomic cardiovascular balance in mice. $J$ Apply Physiol 2004; 96: 2174-78.

94. Dawkis PA, Stockley RA. Animal models of chronic obstructive pulmonary disease. Thorax 2001; 56: 972-7.

95. Fusco LB, Pêgo -Fernandes PM, Xavier AM, Pazetti R, Capelozzi VL, Jatene FB. Modelo experimental de enfisema pulmonar em ratos induzido por papaína. J Pneumol 2002; 28 (1): 1-7.

96. Boyd RL, Fisher MJ, Jaeger MJ. Non-invasive lung function tests in rats with progressive papain-induced emphysema. Respir Physiol 1980; 40: 18190.

97. Korble V, Hurych J, Holusa R. Changes in pulmonary connective tissue after a single intratracheal instillation of papain in the rat. Am Rev Respir Dis 1982; 125: 239-43.

98. Foronjy RF, Mirochnitchenko O, Propokenko O, Lemaitre V, Jia Y, Inouye M, Okada Y, D'Armiento JM. Superoxide dismutase expression attenuates cigarette smoke- or elastase-generated emphysema in mice. Am J Respir Crit Care Med 2006; 173(6): 623-631.

99. Guerassimov A, Hoshino Y, Takubo Y, Turcotte A, Yamamoto M, Ghezzo H, Triantafillopoulos A, Whittaker K, Hoidal JR, Cosio MG. The development 
of emphysema in cigarette smoke-exposed mice is strain dependent. Am J Respir Crit Care Med 2004; 170(9): 974-980.

100. Chung KF, Adcock IM. Multifaceted mechanisms in COPD: inflammation, immunity, and tissue repair and destruction. Eur Respir J 2008; 31(6): 1334-1356.

101. Li H, Cui D, Tong X, Ma N, Gao Y, Cui X, Lu L, Wang D, Liang Y. The role of matrix metalloproteinases in extracellular matrix remodelling in chronic obstructive pulmonary disease rat models. Zhonghua Nei Ke Za Zhi 2002; 41(6): 393-398.

102. Gelb AF, Mckenna Jr RJ, Brenner M, Schein MJ, Zamel N, Fischel R. Lung function 4 years after lung volume reduction surgery for emphysema. Chest 1999; 116:1608-15.

103. West JB. Destruction of mechanical stress in lung, a possible factor in localization of pulmonary disease. Lancet 1971; 1:839-41.

104.Kononov S, Brewer K, Sakai H, Cavalante FSA, Sabayanagam CR, Ingenito EP, Suki B. Roles of mechanical forces and collagem failure in the development of elatase-induced emphysema. Am J Crit Care Med 2001; 164:1920-26.

105. Amato MBP, Barbas CSV, Medeiros DM, Deheinzelin D, Kairalla RA, Carvalho CRR. Improved lung mechanics and oxigenation achieve through a new approuch to mechanical ventilation in ARDS: The importance of reduction the mechanical stress on the lungs. Am Rev Respir Dis 1993; 147:A890,. 
106. Amato MBP, Barbas CSV, Medeiros DM, Schettino GPP, Lorenzi G, Kairalla RA, Deheinzelin D, Morais C, Fernandes E, Takagani TY, Carvalho CRR. Beneficial effects of the "open lung approach" with low distending pressures in ARDS: a prospective randomized study on mechanical ventilation. Am J Respir Crit Care Med 1995;152:1835-46.

107. Amato MBP, Barbas CSV, Medeiros DM, Magaldi RB, Schettino GPP, Lorenzi G, Kairalla RA, Deheinzelin D, Munhoz C, Oliveira R, Takagani TY, Carvalho CRR. Effect of a protective-ventilation strategy on mortality in the acute respiratory distress syndrome. New Engl J Med 1998; 338:347-54.

108. Pratico DB, Vieiro MCC, FitzGerald GA. Chronic obstructive pulmonary disease is associated with an increase in urinary levels of isoprostane F2alpha-III, as index of oxidant stress. Am J Respir Crit care Med 1998; 170817.

109. Groneberg DA, Chung FK. Models of chronic obstructive pulmonary disease. Respiratory Research 2004; 5:18.

110. Shapiro SD. Animal models for chronic obstructive pulmonary disease: age of klotho and Marlboro mice. Am J Respir Cell Mol Biol 2000; 22:4-7.

111. Snider GL. Emphysema: The first two centuries-and beyond: A historical overview, with suggestions for future research:Part 2. Am Rev Respir Dis 1992; 146: 1615-22.

112. Snider GL, Lucey EC, Stone PJ: Animal models of emphysema. Am Rev Respir Dis 1986; 133:149-69. 
113. Kuhn C, Yu SY, Chraplyvy M, Linder HE, Senior RM. The induction of emphysema with elastase. II. Changes in connective tissue. Lab Invest 1976; 34:372-80. 